\title{
Chemically modified field effect transistors: the effect of ion-pair association on the membrane potentials
}

\author{
Peter L.H.M. Cobben ${ }^{\text {a,b }}$, Richard J.M. Egberink ${ }^{a}$, Johan G. Bomer ${ }^{b}$, Piet Bergveld ${ }^{\mathrm{b}}$ \\ and David N. Reinhoudt ${ }^{a, \star}$ \\ Laboratories of " Organic Chemistry and ${ }^{b}$ Bioinformatics, University of Twente, P.O. Box 217, 7500 AE Enschede (The Netherlands)
}

(Received 11 January 1993; in revised form 12 August 1993)

\begin{abstract}
A theoretical model has been developed which relates physically accessible parameters to the formation of a membrane potential. The description is an extension of a theoretical description presented previously by our group, now including divalent cations and ion-pair association. Simulations of the overall membrane potential reveal several factors that may lead to non-Nernstian response curves. For monovalent and divalent cations a reduction in the slope of the response curve (sub-Nernstian response) should virtually always be expected when ion-pair association takes place in the membrane. Ion-pair association of divalent cations and sample anions can lead to a super-Nernstian response. A diffusion potential generally reduces the Nernstian slope of the response curve. In addition, several experimental results are described which illustrate and confirm our theoretical model.
\end{abstract}

\section{Introduction}

For the interpretation of the parameters that influence the overall membrane potential of potentiometric sensors such as a CHEMFET or ISE a three-segment model is often used. The overall membrane potential of a membrane separating two aqueous phases is composed of two boundary and one diffusion potential within the membrane. On the basis of this model it is possible to calculate the potential of a sensing membrane. The recent modification by Morf [1] of a theory which was first developed by Teorell [2] and Meyer and Sievers [3] is such a model. In a contribution of our group the model was further refined to include free and fixed ligands [4]. One of the assumptions of such a theoretical model is the absence of ion-pair formation in the sensing membrane. However, very recently Armstrong [5] showed experimentally in a valinomycin based potassium-selective electrode, containing tetraphenylborate as the anionic site, that the association between a potassium valinomycin complex and tetraphenylborate is strong ( $70 \mathrm{~mol} \%$ of the total tetraphenylborate is present as an ion-pair). The model presented in this

ॠ To whom correspondence should be addressed. paper is a further extension of our previously developed model and can deal with ion-pair formation within the sensing membrane. Also, the presence of divalent cations in the system was studied theoretically. Finally, our recent results of measurements with silver- and lead-selective CHEMFETs demonstrate some typical features of the predicted theoretical response curves.

\section{Experimental}

Chemically modified ion-selective field effect transistors (CHEMFET) were used for the potentiometric measurements. These CHEMFETs consist of a hydrophobic sensing membrane on top of a poly-hydroxyethylmethacrylate (polyHEMA) covered ISFET. The detailed structure of the CHEMFET has been described previously [6,7]. PVC-membrane CHEMFETs were made by solvent casting a solution of $1: 2 \mathrm{wt}$. high-molar-mass PVC (Fluka) and either bis(2-ethylhexyl)sebacate (DOS), bis(2-ethylhexyl)phthalate (DOP), or 2-nitrophenyl octyl ether (o-NPOE) with varying amounts of potassium tetrakis(4-chlorophenyl)borate (KTCPB) and heavy metal ion-selective calix[4]arene based ionophores [7]. The selectivity coef* ficients were determined by the fixed interference method [8]. Corrections for the activity of the salts 
were calculated by the extended Debye-Hückel approximation given by Meier [9].

\section{Model description}

\subsection{System definition}

The sample solution should contain no more than two interfering $1: 2$ or $1: 1$ salts of fixed activity and a varying activity of the primary $1: 2$ or $1: 1$ salt. The reference solution will contain no more than three $1: 2$ or $1: 1$ salts of fixed activity. The cation activities are denoted by $a_{+i}(\mathrm{r})$ and $a_{+i}(\mathrm{~s})$ for the reference and the sample solution respectively. Only one type of anion is present with activity $a_{-}(\mathrm{r})$ and $a_{-}(\mathrm{s})$. The anionic (Y) and cationic $(\mathrm{X})$ sites are lipophilic species that are only present in the membrane phase and have activities $a_{\mathrm{Y}}$ and $a_{\mathrm{X}}$ respectively. The ionophore or ligand (L) is confined to the membrane and has activity $a_{\mathrm{L}}$. All parameters in the membrane phase, except the mobilities $u$, are indicated by a superscript $\left({ }^{m}\right)$.

In analogy with the ion-selective electrode literature, the membrane potential is given by the potential of the (inner) reference solution minus the potential of the sample solution:

$$
E_{\mathrm{M}}=\phi_{\mathrm{r}}-\phi_{\mathrm{s}}=-E_{\mathrm{B}}(\mathrm{r})-E_{\mathrm{D}}+E_{\mathrm{B}}(\mathrm{s})
$$

The overall membrane potential consists of two boundary (or Donnan) potentials $E_{\mathrm{B}}(\mathrm{r})$ and $E_{\mathrm{B}}(\mathrm{s})$, and a diffusion potential $E_{\mathrm{D}}$. In the next sections the route leading to calculation of the diffusion and boundary potentials is outlined.

\subsection{Diffusion potential}

The diffusion potential arises from the difference in mobility of the charged species within the membrane. Analogous to the liquid junction potential the Henderson approximation can be used to calculate this membrane diffusion potential $E_{\mathrm{D}}$ :

$$
\begin{aligned}
E_{\mathrm{D}}= & \phi_{\mathrm{s}}^{\mathrm{m}}-\phi_{\mathrm{r}}^{\mathrm{m}} \\
E_{\mathrm{D}}= & \frac{\Sigma\left|z_{+}\right| u_{+} \Delta a_{+}^{\mathrm{m}}-\Sigma\left|z_{-}\right| u_{-} \Delta a_{-}^{\mathrm{m}}}{\Sigma z_{+}^{2} u_{+} \Delta a_{+}^{\mathrm{m}}+\Sigma z_{-}^{2} u_{-} \Delta a^{\mathrm{m}}} \frac{R T}{F} \\
& \times \ln \frac{\Sigma z_{+}^{2} u_{+} a_{+}^{\mathrm{m}}(\mathrm{r})+\Sigma z_{-}^{2} u_{-} a_{-}^{\mathrm{m}}(\mathrm{r})}{\Sigma z_{+}^{2} u_{+} a_{+}^{\mathrm{m}}(s)+\Sigma z_{-}^{2} u_{-} a_{-}^{\mathrm{m}}(\mathrm{s})}
\end{aligned}
$$

It is obvious from this formula that $\Delta a_{i}^{\mathrm{m}}$ can be defined either as $a_{i}^{\mathrm{m}}(\mathrm{r})-a_{i}^{\mathrm{m}}(\mathrm{s})$ or vice versa; in the computer program the latter definition is used. The calculation of $E_{\mathrm{D}}$ with this formula needs only relative mobilities. The computations of $E_{\mathrm{D}}$ require the activities of all charged species at both interfaces in the membrane. These activities can be calculated from the equilibria at those interfaces, as depicted in the next section.

\subsection{Boundary potential}

The two boundary potentials are defined as the difference between the potential $\phi^{\mathrm{m}}$ in the membrane phase and $\phi$ in the aqueous phase:

$E_{\mathrm{B}}=\phi^{\mathrm{m}}-\phi$

In this model description several equilibria and conservation laws are taken into account.

At the interface, electrochemical equilibrium of the permeable ion $i$ exists between the membrane phase and the aqueous phase:

$\mu_{+i}^{\mathrm{m}}=\tilde{\mu}_{+i}^{\mathrm{m}}$

This can be transformed to eqn. (3):

$$
\begin{aligned}
& \mu_{+i}^{0}+R T \ln a_{+i}+z_{i} F \phi \\
& \quad=\mu_{+i}^{0 \mathrm{~m}}+R T \ln a_{+i}^{\mathrm{m}}+z_{i} F \phi^{\mathrm{m}}
\end{aligned}
$$

in which $\mu_{+i}^{0}$ is the standard chemical potential of cation $i$.

The standard chemical potential of cation $i$ in the membrane phase and the aqueous phase can be combined with the partition coefficient $k_{+i}$, the distribution of a cation over both phases at zero boundary potential:

$k_{+i} \equiv \frac{a_{+i}^{\mathrm{m}}}{a_{+i}}=\exp \left[\frac{\left(\mu_{+i}^{0}-\mu_{+i}^{0 \mathrm{~m}}\right)}{R T}\right]$

Rearrangement of formula (3) and introduction of the boundary potential $E_{\mathrm{B}}$ and the partition coefficient $\mathrm{k}_{+i}$ leads to

$E_{\mathrm{B}}=\left(R T / z_{i} F\right) \ln \left(k_{+i} a_{+i} / a_{+i}^{\mathrm{m}}\right)$

Formula (5) is valid for each cation $i$ and relates for example the activities $a_{+1}^{\mathrm{m}}$ and $a_{+2}^{\mathrm{m}}$ via the boundary potential $E_{\mathrm{B}}$ which is of course identical for cations 1 and 2.

For the anion a similar derivation relates the anion partition coefficient $k_{-}$to the activities of the anion in the membrane and the aqueous phase:

$E_{\mathrm{B}}=\left(R T /\left|z_{i}\right| F\right) \ln \left(a_{-}^{\mathrm{m}} / k_{-} a_{-}\right)$

The free cations and the anion in the membrane phase can associate with several charged species. In Table 1A all possible associates with their association constants are given.

The free cations can also be complexed by the neutral ligand:

$a_{\mathrm{L}}^{\mathrm{m}}+a_{+i}^{\mathrm{m}} \stackrel{\beta_{i}}{\rightleftarrows} a_{\mathrm{L}}^{\mathrm{m}} a_{+i}^{\mathrm{m}}$

where $\beta_{i}$ is the complexation constant of the ionophore with cation $i$. 
TABLE 1. Selected association within the membrane phase

\begin{tabular}{|c|c|c|c|}
\hline \multicolumn{2}{|c|}{ A, without ionophore } & \multicolumn{2}{|c|}{$\mathrm{B}$, with ionophore } \\
\hline Species & $\begin{array}{l}\text { Association } \\
\text { constant }\end{array}$ & Species & $\begin{array}{l}\text { Association } \\
\text { constant }\end{array}$ \\
\hline $\begin{array}{l}a_{+i} a_{-}^{a} \\
a_{+i} a_{Y} a^{a} \\
a_{+i}\left(a_{Y}\right)_{\mathbf{Z}} \\
a_{+i} a_{Y} a_{-} \\
a_{\mathbf{X}} a_{-} \\
a_{\mathbf{X}} a_{++Y}\end{array}$ & $\begin{array}{l}K_{-} \\
K_{\mathbf{Y}} \\
K_{\mathbf{Y Z}} \\
K_{\mathbf{Y}-} \\
K_{\mathbf{X}-} \\
K_{\mathbf{X Y}}\end{array}$ & $\begin{array}{l}a_{+i} a_{\mathrm{L}} \\
a_{+i} a_{\mathrm{L}} a_{-} \\
a_{+i} a_{\mathrm{L}}\left(a_{-}\right)_{\mathbf{z}} \\
a_{+i} a_{\mathrm{L}} a_{\mathrm{Y}} \\
a_{+i} a_{\mathrm{L}}\left(a_{\mathrm{Y}}\right)_{\mathrm{z}} \\
a_{+i} a_{\mathrm{L}} a_{\mathrm{Y}} a_{-}\end{array}$ & $\begin{array}{l}\beta \\
K_{\mathrm{L}-} \\
K_{\mathrm{L}-\mathbf{z}} \\
K_{\mathrm{LY}} \\
K_{\mathrm{LYz}} \\
K_{\mathrm{L}-\mathrm{Y}}\end{array}$ \\
\hline
\end{tabular}

${ }^{a}$ Only for divalent cations.

In the associates of free cations and anion mentioned in Table $1 \mathrm{~A}$ the ionophore can play a role and therefore the set in Table 1A is expanded with the associates in which the ionophore is involved (see Table 1B).

Together with equilibrium equations, a set of conservation laws is needed to solve this system mathematically. The following three mass conservation laws can be obtained. First of all there will be conservation of the total amount of ligand $L_{\text {tot }}$. The concentration of all species containing a ligand (see Table 1B) plus the amount of free ligand equals the total concentration of ligand $L_{\text {tor }}$.

$$
\begin{aligned}
L_{\text {tot }}= & c_{\mathrm{L}}^{\mathrm{m}}+\Sigma c_{+i}^{\mathrm{m}} c_{\mathrm{L}}^{\mathrm{m}}+\Sigma\left(z_{i}-1\right) c_{+i}^{\mathrm{m}} c_{\mathrm{L}}^{\mathrm{m}} c_{-}^{\mathrm{m}} \\
& +\Sigma c_{+i}^{\mathrm{m}} c_{\mathrm{L}}^{\mathrm{m}}\left(c_{-}^{\mathrm{m}}\right)_{\mathrm{z}}+\Sigma\left(z_{i}-1\right) c_{+i}^{\mathrm{m}} c_{\mathrm{L}}^{\mathrm{m}} c_{\mathrm{y}}^{\mathrm{m}} \\
& +\Sigma c_{+i}^{\mathrm{m}} c_{\mathrm{L}}^{\mathrm{m}}\left(c_{\mathrm{y}}^{\mathrm{m}}\right)_{\mathrm{z}}+\Sigma\left(z_{i}-1\right) c_{+i}^{\mathrm{m}} c_{\mathrm{L}}^{\mathrm{m}} c_{\mathrm{y}}^{\mathrm{m}} c_{-}^{\mathrm{m}}
\end{aligned}
$$

Secondly, the concentrations of free and associated anionic sites $Y$ add up to the total concentration of anionic sites $Y_{\text {tot }}$.

$$
\begin{aligned}
Y_{\text {tot }}= & c_{\mathrm{y}}^{\mathrm{m}}+\Sigma\left(z_{i-1}\right) c_{+i}^{\mathrm{m}} c_{\mathrm{y}}^{\mathrm{m}}+\Sigma c_{+i}^{\mathrm{m}}\left(c_{\mathrm{y}}^{\mathrm{m}}\right)_{\mathrm{z}} \\
& +\Sigma\left(z_{i-1}\right) c_{+i}^{\mathrm{m}} c_{\mathrm{y}}^{\mathrm{m}} c_{-}^{\mathrm{m}}+\Sigma\left(z_{i-1}\right) c_{+i}^{\mathrm{m}} c^{\mathrm{m}} c_{\mathrm{y}}^{\mathrm{m}} \\
& +c_{\mathrm{x}}^{\mathrm{m}} c_{\mathrm{y}}^{\mathrm{m}}+\Sigma c_{+i}^{\mathrm{m}} c_{\mathrm{L}}^{\mathrm{m}}\left(c_{\mathrm{y}}^{\mathrm{m}}\right)_{\mathrm{z}} \\
& +\Sigma\left(z_{i-1}\right) c_{+i}^{\mathrm{m}} c_{\mathrm{L}}^{\mathrm{m}} c_{\mathrm{y}}^{\mathrm{m}} c_{-}^{\mathrm{m}}
\end{aligned}
$$

The third conservation law concerns the total amount of cationic sites $X_{\text {tot }}$ :

$X_{\text {tot }}=c_{\mathrm{x}}^{\mathrm{m}}+c_{\mathrm{x}}^{\mathrm{m}} c_{-}^{\mathrm{m}}+c_{\mathrm{x}}^{\mathrm{m}} c_{\mathrm{y}}^{\mathrm{m}}$

In order to complete the mathematical set of equations another approximation is made. Except for the space charge regions at the interfaces, electroneutrality is assumed in the bulk of the membrane:

$$
\begin{aligned}
c_{\mathrm{y}}^{\mathrm{m}}+c_{-}^{\mathrm{m}}= & c_{\mathrm{X}}^{\mathrm{m}}+\Sigma z_{i} c_{+i}^{\mathrm{m}}+\Sigma\left(z_{i-1}\right) c_{+i}^{\mathrm{m}} c_{-}^{\mathrm{m}} \\
& +\Sigma\left(z_{i-1}\right) c_{+1}^{\mathrm{m}} c_{\mathrm{y}}^{\mathrm{m}}+\Sigma z_{i} c_{+i}^{\mathrm{m}} c_{\mathrm{L}}^{\mathrm{m}} \\
& +\Sigma\left(z_{i-1}\right) c_{+i}^{\mathrm{m}} c_{\mathrm{L}}^{\mathrm{m}} c_{\mathrm{y}}^{\mathrm{m}}
\end{aligned}
$$

For calculation of all the concentrations of the membrane species formulae (5) and (6) can only be used in combination with formulae (8)-(11) if we assume a unit activity coefficient. The calculated equilibrium concentrations of all species are situated in the membrane at the interface, just outside the space charge region.

The mathematical problem is now unambiguous, but because of the numerous equations (containing square numbers) only an iterative procedure provides a numerical solution. This procedure starts with an estimated value of $c_{\mathrm{y}}^{\mathrm{m}}$ and $c_{+1}^{\mathrm{m}}$. From formulae (5) and (6), $c_{+2}^{\mathrm{m}}, c_{+3}^{\mathrm{m}}$, and $c_{-}^{\mathrm{m}}$ are known. Substitution of these concentrations and partition constants, charge and the association constants in the mass conservation law of total ligand $L_{\text {tot }}$ gives an estimated concentration of free ligand $c_{\mathrm{L}}^{\mathrm{m}}$ (formula (8)). These estimated concentrations are combined with the mass conservation law of anionic sites $Y_{\text {tot }}$ (formula (9)) and the assumption of electroneutrality (formula (11)) in the bulk of the membrane to give a new estimate of $c_{+1}^{\mathrm{m}}$ (and therefore $E_{\mathrm{B}}$ ) and $c_{\mathrm{y}}^{\mathrm{m}}$, which completes one iteration. These iterations are continued until the absolute value of the sum of all charges is less than at least 0.01 times the lowest concentration. In this way the boundary potential (eqns. (5) and (6)) at both interfaces, the concentrations of all species (Table 1) and (therefore) the diffusion potential (eqn. (2)) can be calculated. By combining these three potentials, as stated at the beginning of this paragraph, the total membrane potential can be evaluated for several universal simulations.

\section{Results and discussion}

In order to obtain a better understanding of the (theoretical) influence of the above mentioned parameters on the overall membrane potential, a series of simulations was performed. The contribution to the membrane potential is divided into its components, the boundary and diffusion potentials. In these simulations the concentration of the cation in the inner electrolyte solution is fixed at $10^{-2} \mathrm{~mol} \mathrm{l}^{-1}$, unless stated otherwise. The concentration of the primary cation $c_{+1}(\mathrm{~s})$ in the sample solution varies from $10^{-6}$ to $10^{-2} \mathrm{~mol} \mathrm{l}^{-1}$. In all figures the overall membrane potential is depicted. Some representative data of the calculated concentrations of the electroactive species are listed in Appendices $\mathbf{A}-\mathrm{H}$.

\subsection{Boundary potential}

\subsubsection{Monovalent cations}

With the first set of simulations we investigated the influence of the association constants $\left(\beta_{1}\right.$ and $\left.\beta_{2}\right)$ of the complexes between both the primary and the inter- 


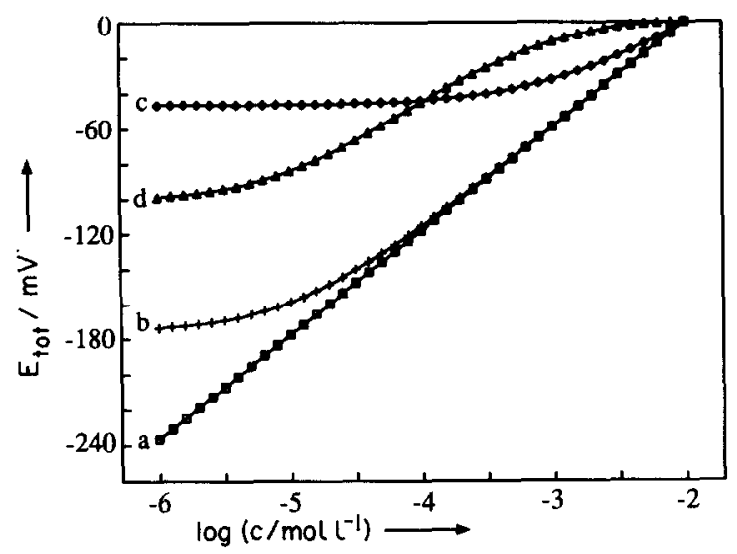

Fig. 1. The influence of the association constant $\beta$ on the potentiometric response of monovalent cations: (a) $\beta_{1}=10^{9} 1 \mathrm{~mol}^{-1}, c_{+2}=0$ mol l-1; (b) $\beta_{1}=10^{9} \mathrm{l} \mathrm{mol}^{-1}, \beta_{2}=10^{5} 1 \mathrm{~mol}^{-1}, c_{+2}=0.1 \mathrm{~mol} \mathrm{l}^{-1}$; (c) $\beta_{1}=10^{5} 1 \mathrm{~mol}^{-1}, \beta_{2}=10^{1} \mathrm{lmol}^{-1}$; (d) $\beta_{1}=10^{13} 1 \mathrm{~mol}^{-1}, \beta_{2}=$ $10^{9} 1 \mathrm{~mol}^{-1}$.

fering cations with the ligand. The starting situation is a membrane in which anionic sites $\left(Y_{\text {tot }}=6 \times 10^{-4}\right.$ mol 1 $\left.{ }^{-1}\right)$ and ionophore $\left(L_{\mathrm{tot}}=1 \times 10^{-3} \mathrm{~mol} \mathrm{l}^{-1}\right)$ are present. The cation $c_{+1}$ and anion $\left(c_{-}\right)$of the sample solution have an identical partition $\left(10^{-6}\right)$ to the membrane phase. The cation-ionophore complex $\left(c_{\mathrm{L}}^{\mathrm{m}} c_{+1}^{\mathrm{m}}\right)$ of the primary cation has an association constant $\beta_{1}$ of $10^{9} 1 \mathrm{~mol}^{-1}$. The ratio of the total amount of ionophore $\mathrm{L}\left(1 \times 10^{-3} \mathrm{~mol}^{-1}\right)$ and anionic site $\mathrm{Y}\left(6 \times 10^{-4}\right.$ mol $\left.1^{-1}\right)$ is fixed at a value often used under experimental conditions *.

Without interfering ion, a Nernstian response (60 $\mathrm{mV}$ per decade) is predicted over the whole concentration range (Fig. 1(a)). This simulation shows that the amount of free primary cation in the membrane is constant (Appendix A, $c_{+1}^{\mathrm{m}}=1.5 \times 10^{-9} \mathrm{~mol} \mathrm{l}^{-1}$ ), which leads to the Nernstian response according to eqn. (5). The complex concentration $\left(c_{\mathrm{L}}^{\mathrm{m}} \mathrm{c}_{+1}^{\mathrm{m}}\right)$ is constant and equal to the concentration of anionic sites $\left(c_{\mathrm{Y}}^{\mathrm{m}}=6 \times 10^{-4} \mathrm{~mol}^{-1}\right)$. Sample anions are hardly present at a primary cation concentration $c_{+1}$ of $10^{-6}$ mol $1^{-1}\left(c_{-}^{\mathrm{m}}=6.7 \times 10^{-16} \mathrm{~mol} \mathrm{l}^{-1}\right)$. However, when the cation concentration in the sample solution is increased, the absolute value of the boundary potential rises and this promotes the transfer of free sample anions to the membrane phase. Thus, a ten-fold increase in primary cation in the sample solution causes

\footnotetext{
* Theoretically no optimum ratio of anionic site to ionophore concentration is defined in the case of a monovalent cation (ref. 11). A Nernstian response towards monovalent cations can of course only be expected if the concentration of the anionic site is less than the amount of ionophore. A concentration of $60 \mathrm{~mol} \%$ anionic site relative to the ionophore is applicable for a potassium-selective CHEMFET (ref. 12).
}

a hundred times higher sample anion concentration in the membrane.

The introduction of an interfering cation of concentration $c_{+2}=0.1 \mathrm{~mol} \mathrm{l}^{-1}$ lowers the slope of the response curve at low concentrations of the primary cation (Fig. 1(b)). At a primary ion concentration $c_{+1}$ in the sample solution of $10^{-6} \mathrm{~mol}^{-1}$, the concentration of the complex with the interfering cation (Appendix $\mathrm{A}, c_{\mathrm{L}}^{\mathrm{m}} c_{+2}^{\mathrm{m}}=4.7 \times 10^{-4} \mathrm{~mol} \mathrm{l}^{-1}$ ) is larger than the concentration of the complex with the primary cation $\left(c_{\mathrm{L}}^{\mathrm{m}} c_{+1}^{\mathrm{m}}=1.1 \times 10^{-4} \mathrm{~mol}^{-1}\right)$. In the Nernstian region of the simulated curve, the primary cation-ligand complex concentration is larger than that of the interfering cation-ligand complex. In the membrane, the concentration of the interfering cation $c_{+2}^{\mathrm{m}}$ is always larger than the concentration of the primary cation $c_{+1}^{\mathrm{m}}$ but not constant. At a change in primary cation $c_{+1}$ in the aqueous phase, e.g. from $c_{+1}=10^{-3} 1 \mathrm{~mol}$ to $c_{+1}$ $=10^{-2} \mathrm{Imol}$, the concentration of primary cation in the membrane $c_{+1}^{\mathrm{m}}$ remains the same $\left(c_{+1}^{\mathrm{m}}=1.5 \times 10^{-9}\right.$ mol 1 ${ }^{-1}$, Appendix A). Therefore, the boundary potential $E_{\mathrm{B}}$ changes by $58.8 \mathrm{mV}$ and according to formula (5) this causes a decrease in the concentration of the interfering cation in the membrane $c_{+2}^{\mathrm{m}}$ from $1.5 \times 10^{-7}$ mol $1^{-1}$ (when $c_{1}=10^{-3}$ ) to $1.5 \times 10^{-8} \mathrm{~mol} \mathrm{l}^{-1}$ (when $c_{1}=10^{-2}$ ). The increase in sample anions in the membrane on changing the primary cation concentration in the sample solution is less pronounced $\left(c_{+1}=10^{-4}\right.$ $\mathrm{mol} \mathrm{l}^{-1}: c_{-}^{\mathrm{m}}=7.3 \times 10^{-9} \mathrm{~mol} \mathrm{l}^{-1} ; c_{+1}=10^{-2} \mathrm{~mol} \mathrm{l}^{-1}$ : $c_{-}^{\mathrm{m}}=7.4 \times 10^{-7} \mathrm{~mol}^{-1}$ ) because the concentration of the anions in the sample solution is fixed via the concentration of the interfering salt. The calculated potentiometric selectivity coefficient $\left(\log K_{i, j} \approx-4\right)$ resembles the ratio of the complexation constants $\beta_{1}$ and $\beta_{2}\left(10^{4}\right)$.

The effect of the absolute values of the association constants of both the complexes between the interfering $\beta_{2}$ and the primary $\beta_{1}$ cations with the ionophore on the theoretical response curve is depicted in Fig. 1(c) and 1(d). If the absolute value of the association constants is lowered $\left(\beta_{1}=10^{5} 1 \mathrm{~mol}^{-1}, \beta_{2}=10\right.$ $1 \mathrm{~mol}^{-1}$, see Fig. 1(c)) the selectivity is reduced. The lower selectivity is due to the lower and varying amount of primary cation-ligand complex $c_{\mathrm{L}}^{\mathrm{m}} c_{+1}^{\mathrm{m}}$ (Appendix A) compared with the case in which the association constants are higher (Fig. 1(b)). So if the association constant is lowered, the concentration of the primary cation-ligand complex decreases and buffering of the free cation concentration via the equilibrium between complexed and free ionophore is reduced.

Increasing the two association constants $\left(\beta_{1}=10^{13}\right.$ $1 \mathrm{~mol}^{-1}, \beta_{2}=10^{9} \mathrm{l} \mathrm{mol}^{-1}$, see Fig. 1(d)) shows two effects. The slope of the response curve is lowered from 60 to $43 \mathrm{mV}$ per decade. The high association 


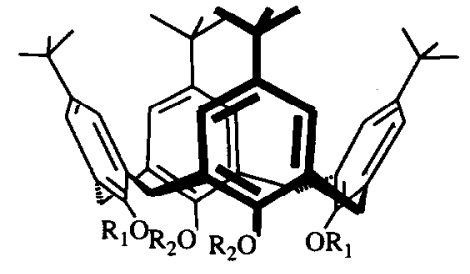

I $\mathrm{R}_{1}=\mathrm{CH}_{2} \mathrm{CH}_{2} \mathrm{SCH}_{3} ; \mathrm{R}_{2}=\mathrm{H}$

$2 \mathrm{R}_{1}=\mathrm{R}_{2}=\mathrm{CH}_{2} \mathrm{CH}_{2} \mathrm{SCH}_{3}$

$3 \mathrm{R}_{1}=$ propyl; $\mathrm{R}_{2}=\mathrm{CH}_{2} \mathrm{CH}_{2} \mathrm{SCH}_{3}$

$4 \mathrm{R}_{1}=$ propyl; $\mathrm{R}_{2}=\mathrm{CH}_{2} \mathrm{C}(\mathrm{O}) \mathrm{N}(\mathrm{Me})_{2}$

$5 \mathrm{R}_{1}=$ propyl; $\mathrm{R}_{2}=\mathrm{CH}_{2} \mathrm{CH}_{2} \mathrm{OCH}_{2} \mathrm{C}(\mathrm{O}) \mathrm{N}(\mathrm{Me})_{2}$

Scheme 1.

constant $\beta_{1}$ reduces the concentration of the primary cation in the membrane and increases the boundary potential (eqn. (5)) which promotes the transfer of sample anions to the membrane. Even at low primary cation concentrations $\left(c_{+1}=10^{-5}-10^{-4} \mathrm{~mol} \mathrm{l}^{-1}\right)$ the concentration of the free sample anion in the membrane $c_{-}^{\mathrm{m}}$ is of the same order of magnitude as the concentration of the anionic site $c_{Y}^{\mathrm{m}}$ (Appendix A). Therefore the concentration of free cation in the membrane $c_{+1}^{\mathrm{m}}$ is not constant and the slope is decreased. This is the first example of a mechanism which explains the reduction of the slope; the diffusion potential might be the second reason in special cases (vide infra). At high cation concentrations $\left(c_{+1}=10^{-2} \mathrm{~mol} \mathrm{l}^{-1}\right)$ the slope is reduced to zero and further addition of salt leads to an anion response as has been reported earlier [4]. Buck et al. [12] reported a valinomycin based potassium-selective electrode which showed anion response when lipophilic sample anions were used.

According to the model calculations performed in this paper, the association constant of the cation-ionophore complex will influence the slope of the response curve especially at high primary ion concentration. A higher association constant will correspond to a lower slope. Therefore, CHEMFETs were prepared with several similar ionophores in the PVC membranes that covered the polyHEMA hydrogel. The hydrogel was conditioned with 0.01 molar silver nitrate $\left(\mathrm{HNO}_{3}, \mathrm{pH}\right.$ 4) prior to membrane deposition. A typical membrane consisted of 2 wt.\% highly silver-selective [7] calix[4]arene 1, 2, or 3 (Scheme 1), 0.8 wt.\% KTCPB, 32.5 wt.\% PVC, and 64.7 wt.\% DOS. Comparison of the response curves of the three calix[4]arene based ionophores measured in $0.1 \mathrm{M} \mathrm{Ca}\left(\mathrm{NO}_{3}\right)_{2}$ (Fig. 2) would indicate differences in association constants $\left(K^{\mathrm{Ag}}(\mathbf{1}) \approx\right.$ $\left.K^{\mathrm{Ag}}(\mathbf{3})<K^{\mathrm{Ag}}(\mathbf{2})\right) *$.

\footnotetext{
* Membrane transport experiments (SLM) in NPOE as a solvent indicate that the association constant of the $1 . \mathrm{Ag}^{+}$complex is a factor of 160 lower than of the $2 \mathrm{Ag}^{+}$complex [15].
}

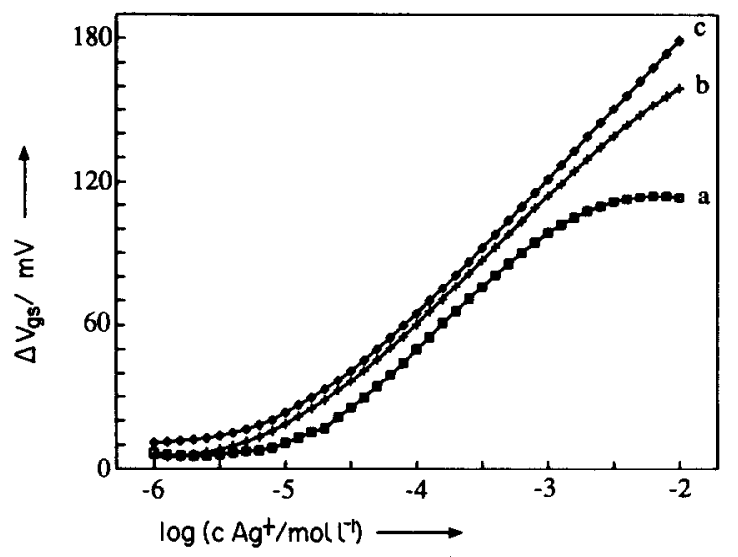

Fig. 2. $\mathrm{Ag}^{+}$responses of CHEMFETs containing different calix[4]arene ionophores in $0.1 \mathrm{M} \mathrm{Ca}\left(\mathrm{NO}_{3}\right)_{2}$ : (a) ionophore 2; (b) ionophore 3; (c) ionophore 1 .

The tetrasubstituted 2 exhibits the largest deviation from the Nernstian slope and subsequently the strongest association with the silver cation. The disubstituted compounds 1 and 3 responded almost identically. However, the less crowded calix[4]arenc 1 yiclds a more linear slope than receptor molecule 3. Therefore, the association constant of compound 1 is expected to be the lowest.

A second variation which has been studied theoretically is the ion pair association within the membrane phase. Armstrong [5] showed experimentally in a valinomycin based potassium-selective electrode, containing tetraphenylborate as the anionic site, that the association between a potassium valinomycin complex and tetraphenylborate is strong ( $70 \mathrm{~mol} \%$ of total tetraphenylborate is present as an ion pair). Therefore,

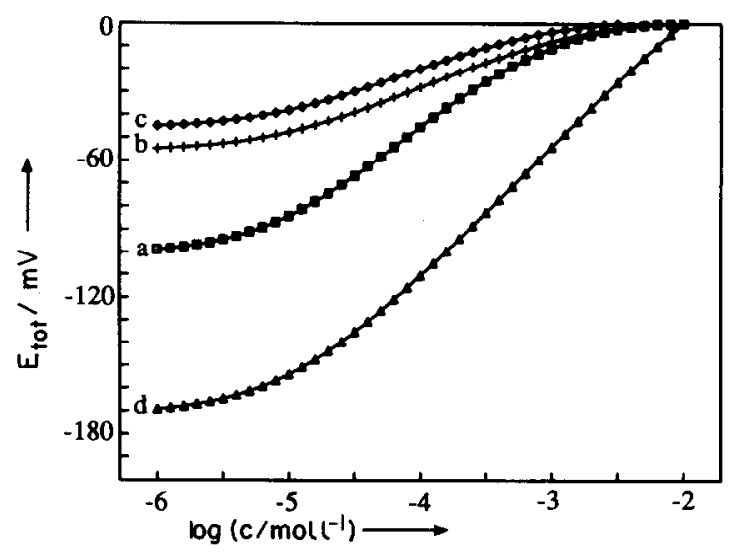

Fig. 3. The influence of ion-pair association in the membrane phase on the potentiometric response of monovalent cations: (a) $\beta_{1}=10^{13}$ $1 \mathrm{~mol}^{-1}, \beta_{2}=10^{9} \mathrm{I} \mathrm{mol}^{-1}$, no association; (b) $K_{\mathrm{Yz1}}=K_{\mathrm{Yz2}}=10^{15}$ $1^{2} \mathrm{~mol}^{-2}$; (c) $K_{\mathrm{LYz1}}=K_{\mathrm{LYz2}}=10^{17} \mathrm{l}^{3} \mathrm{~mol}^{-3}$; (d) $K_{\mathrm{L}-\mathrm{zl}}=K_{\mathrm{L}-\mathrm{z} 2}=$ $10^{17} 1^{3}$ mol ${ }^{3}$. Curve (a) is identical with curve (d) from Fig. 1 . 
three different associates have to be considered: an associate between the cation and the anionic site $\left(c_{+i}^{\mathrm{m}}\left(c_{\mathrm{Y}}^{\mathrm{m}}\right)_{\mathrm{z}}, K_{\mathrm{Yz}}\right)$, between the cation, the ionophore, and sample anions $\left(c_{+i}^{\mathrm{m}} c_{\mathrm{L}}^{\mathrm{m}}\left(c_{-}^{\mathrm{m}}\right)_{\mathrm{z}}, K_{\mathrm{L}-\mathrm{z}}\right)$, and between the cation, the ionophore, and the anionic site $\left(c_{+i}^{\mathrm{m}} \mathrm{c}_{\mathrm{L}}^{\mathrm{m}}\left(c_{\mathrm{Y}}^{\mathrm{m}}\right)_{2}, K_{\mathrm{LY}}\right)$ (see also Table 1). In order to vizualize the effect of these associates, simulations were performed starting from the conditions of Fig. 1(d) (Fig. 3(a)). An association between the free cation and the anionic site $\left(c_{+i}^{\mathrm{m}}\left(c_{\mathrm{Y}}^{\mathrm{m}}\right)_{\mathbf{z}}, K_{\mathrm{Yz}}\right)$ reduces the free cation and free anionic site concentrations in the membrane (Appendix B). At a certain cation concentration $c_{+1}$ the membrane potential increases and sample anions are extracted into the membrane. The sample anions in the membrane $\left(c_{-}^{\mathrm{m}}\right)$ exceed the anionic site concentration at all primary cation concentrations in the sample and the slope decreases (see Fig. 3, compare (a) and (b)). The same effect is observed if an associate is formed between the cation, ionophore, and anionic site $\left(c_{+i}^{\mathrm{m}} c_{\mathrm{L}}^{\mathrm{m}}\left(c_{\mathrm{Y}}^{\mathrm{m}}\right)_{\mathrm{z}}, K_{\mathrm{LY} \mathbf{z}}\right)$. The concentration of free sample anions in the membrane increases and the slope is lowered (see Fig. 3, compare (a) with (c)). However, an associate between the free cation, ionophore, and sample anions in the membrane $\left(c_{+i}^{\mathrm{m}} c_{\mathrm{L}}^{\mathrm{m}}\left(c_{-}^{\mathrm{m}}\right)_{z}, K_{\mathrm{L}-\mathrm{z}}\right)$ shows a different effect. The associate binds sample anions $\left(c_{-}^{\mathrm{m}}\right)$ and the slope is restored to over $50 \mathrm{mV}$ per decade (see Fig. 3, compare (a) and (d)).

\subsubsection{Divalent cations}

Most of the simulations with divalent cations show the same tendency, but some marked differences appear. The partition of the ions $\left(10^{-6}\right)$, the complex constant of the cations with the ionophore $\left(\beta_{1}=10^{9}\right.$ $\left.1 \mathrm{~mol}^{-1}\right)$, and the amount of ionophore $\left(L_{\mathrm{tot}}=1 \times 10^{-3}\right.$ mol $1^{-1}$ ) are kept identical with the situation for the monovalent cations. The amount of anionic site $Y_{\text {tot }}$ is raised to $1.6 \times 10^{-3} \mathrm{~mol}^{-1}$ because one divalent cation electrically neutralizes two anionic sites. Recently, Eugster et al. [10] reported that at an ionophore concentration $L_{\text {tot }}$ of $1 \times 10^{-3} \mathrm{~mol} \mathrm{l}^{-1}, 1.6 \times 10^{-3}$ mol $\mathrm{l}^{-1}$ would be the optimum concentration of anionic site $Y_{\text {tot }}$ for divalent cations.

Without interfering cations a Nernstian response of $30 \mathrm{mV}$ per decade is found over the concentration range $c_{+1}$ from $10^{-6}$ to $10^{-2}$ mol $1^{-1}$ (Fig. 4(a)). Again the concentration of the primary cation $c_{+1}^{\mathrm{m}}$ is constant (Appendix C, $4 \times 10^{-9} \mathrm{~mol} \mathrm{l}^{-1}$ ) which is responsible for the Nernstian slope. Sample anions are excluded at low sample cation concentration $\left(c_{+1}=10^{-6} \mathrm{~mol}^{-1}\right.$, $\left.c_{-}^{\mathrm{m}}=3.2 \times 10^{-14} \mathrm{~mol} \mathrm{l}^{-1}\right)$. At higher cation concentrations more sample anions are extracted. In the case of divalent cations the increase in sample anions is $10^{3}$ per two decades. The simulation with an interfering

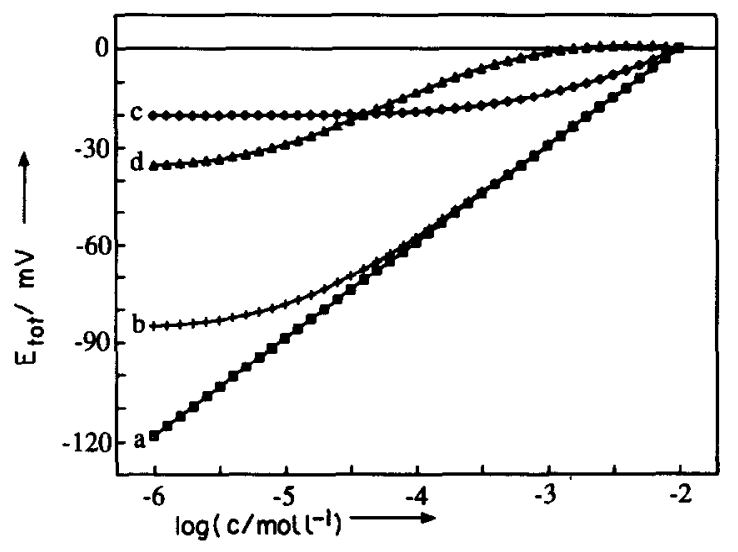

Fig. 4. The influence of the association constant $\beta$ on the potentio metric response of divalent cations: (a) $\beta_{1}=10^{9} 1 \mathrm{~mol}^{-1}, \beta_{2}=0.1$ $1 \mathrm{~mol}^{-1}$; (b) $\beta_{1}=10^{9} 1 \mathrm{~mol}^{-1}, \beta_{2}=10^{5} 1 \mathrm{~mol}^{-1}$; (c) $\beta_{1}=10^{5} 1 \mathrm{~mol}^{-1}$, $\beta_{2}=10^{1} 1 \mathrm{~mol}^{-1}$; (d) $\beta_{1}=10^{17} 1 \mathrm{~mol}^{-1}, \beta_{2}=10^{13} \mathrm{lmol}^{-1}$.

salt $\left(c_{+2} 0.1 \mathrm{~mol} \mathrm{l}^{-1}\right)$ shows a similar effect to that observed for monovalent cations. At a low primary cation concentration the second cation interferes and lowers the slope (Fig. 4(b)).

At higher concentrations of the primary cation $c_{+1}$ the slope is Nernstian ( $30 \mathrm{mV}$ per decade). The increase in sample anions in the membrane is again less pronounced than when the interfering salt is absent. When the association constants are low $\left(\beta_{1}=10^{5}\right.$ $1 \mathrm{~mol}^{-1}, \beta_{2}=10 \mathrm{I} \mathrm{mol}^{-1}$, see Fig. $4(\mathrm{c})$ ), the selectivity is reduced. The buffering effect of the complexed $c_{\mathrm{L}}^{\mathrm{m}} c_{+1}^{\mathrm{m}}$ and free ionophore $c_{\mathrm{L}}^{\mathrm{m}}$ is lowered because of the low complexation constant. At higher association constants of the cation and the ionophore $\left(\beta_{1}=10^{17}\right.$ $1 \mathrm{~mol}^{-1}, \beta_{2}=10^{13} 1 \mathrm{~mol}^{-1}$, see Fig. 4(d)), the linear part of the slope is lowered to roughly $20 \mathrm{mV}$ per decade at intermediate cation concentration in the sample solution. A further increase in the cation concentration $\left(c_{+1} \approx 10^{-2} \mathrm{~mol} \mathrm{1}^{-1}\right)$ in the solution introduces a maximum in the response curve, which was already observed for monovalent cations at lower association constants (compare Fig. 1).

The number of associates which theoretically can be found in the membrane in the case of a divalent cation is nine (see Table 1). In order to illustrate the difference Fig. 4(d) shows the reference situation. Four different associated species without ionophore are taken into account (Table 1A): an associate between a cation and one sample anion $\left(c_{+i}^{\mathrm{m}} c_{-}^{\mathrm{m}}, K_{-}\right)$, a cation and one anionic site $\left(c_{+i}^{\mathrm{m}} c_{\mathrm{Y}}^{\mathrm{m}} c_{-}^{\mathrm{m}}, K_{\mathrm{Y}}\right)$, a cation and two anionic sites $\left(c_{+i}^{\mathrm{m}}\left(c_{\mathrm{Y}}^{\mathrm{m}}\right)_{\mathrm{z}}, K_{\mathrm{Yz}_{\mathrm{z}}}\right)$, and a cation and one sample anion and one anionic site $\left(c_{+i}^{\mathrm{m}} c_{\mathrm{Y}}^{\mathrm{m}}, K_{\mathrm{Y}-}\right)$. All four associates reduce the free cation concentration $c_{+1}^{\mathrm{m}}$ compared with the situation without association in the membrane (Fig. 5(a)). Consequently, the boundary po- 


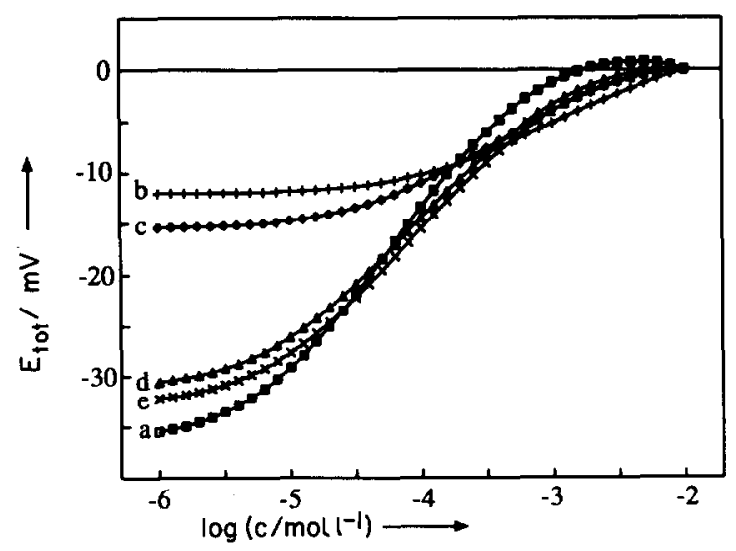

Fig. 5. The influence of ion-pair association in the membrane phase on the potentiometric response of divalent cations: (a) $\beta_{1}=10^{17}$ $1 \mathrm{~mol}^{-1}, \beta_{2}=10^{13} \mathrm{Imol}^{-1}$, no association; (b) $K_{-1}=K_{-2}=10^{15}$ $\mathrm{l}^{2} \mathrm{~mol}^{-2}$; (c) $K_{\mathrm{Y} 1}=K_{\mathrm{Y} 2}=10^{15} 1^{3} \mathrm{~mol}^{-3}$; (d) $K_{\mathrm{Yz}_{1}}=K_{\mathrm{Yz} 2}=10^{17}$ $\mathrm{l}^{3} \mathrm{~mol}^{-3}$; (e) $K_{\mathrm{Y}-1}=K_{\mathrm{Y}-2}=10^{17} \mathrm{l}^{3} \mathrm{~mol}^{-3}$. Curve (a) is identical with curve (d) from Fig. 4.

tential is raised (Appendix D) and more sample anions are extracted to the membrane phase. This results in a decrease in the slope (compare Fig. 5(b)-(e) with 5(a)).

When the ionophore is included in these associates there is a different response. One of these associates, namely with the ionophore and one anionic site $\left(c_{+i}^{\mathrm{m}} c_{\mathrm{L}}^{\mathrm{m}} c_{\mathrm{Y}}^{\mathrm{m}}, K_{\mathrm{LY}}\right.$, Fig. $\left.6(\mathrm{~b})\right)$, also results in a decreased slope (compare Fig. 6(a) and (b)). Two other associates, either with two sample anions $\left(c_{+i}^{\mathrm{m}} c_{\mathrm{L}}^{\mathrm{m}}\left(c_{-}^{\mathrm{m}}\right)_{z}, K_{\mathrm{L}-\mathrm{z}}\right.$, Fig. $6(c))$ or two anionic sites $\left(c_{+\mathrm{i}}^{\mathrm{m}} c_{\mathrm{L}}^{\mathrm{m}}\left(c_{\mathrm{Y}}^{\mathrm{m}}\right)_{\mathrm{z}}, K_{\mathrm{LYz}}\right.$, Fig. 6(d)) show a slight increase in slope to 21 and $19 \mathrm{mV}$ per decade respectively.

However, the associates with only one sample anion $\left(c_{+i}^{\mathrm{m}} c_{\mathrm{L}}^{\mathrm{m}} c_{-}^{\mathrm{m}}, K_{\mathrm{L}-}\right.$, Fig. $\left.7(\mathrm{~b})\right)$ or one sample anion and one anionic site $\left(c_{+i}^{\mathrm{m}} c_{\mathrm{L}}^{\mathrm{m}} c_{\mathrm{Y}}^{\mathrm{m}} c_{-}^{\mathrm{m}}, K_{\mathrm{L}-\mathrm{Y}}\right.$, Fig. $\left.7(\mathrm{c})\right)$ are ex-

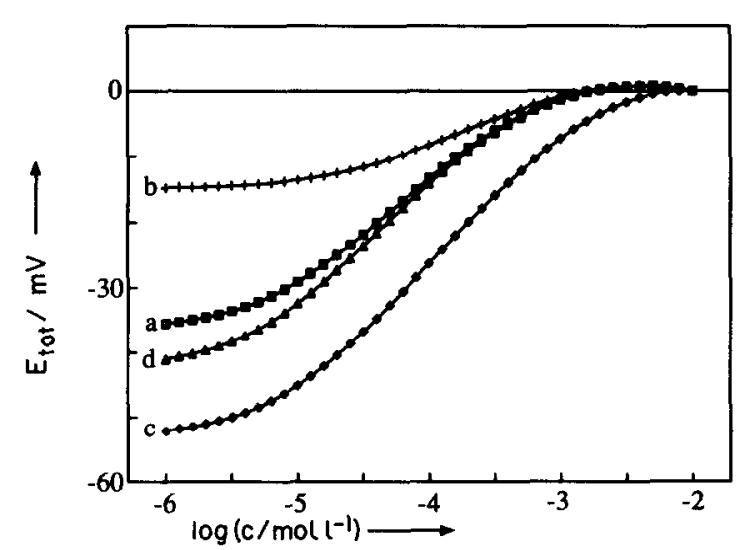

Fig. 6. The influence of ion pair association in the membrane phase on the potentiometric response of divalent cations: (a) $\beta_{1}=10^{17}$ $1 \mathrm{~mol}^{-1}, \beta_{2}=10^{13} 1 \mathrm{~mol}^{-1}$, no association; (b) $K_{\mathrm{LY} 1}=K_{\mathrm{LY} 2}=10^{15}$ $\mathrm{l}^{2} \mathrm{~mol}^{-2}$; (c) $K_{\mathrm{L}-\mathrm{z} 1}=K_{\mathrm{L}-\mathrm{z2}}=10^{15} \mathrm{l}^{4} \mathrm{~mol}^{-4}$; (d) $K_{\mathrm{LYz1}}=K_{\mathrm{LYz} 2}=$ $10^{17} 1^{4} \mathrm{~mol}^{-4}$. Curve (a) is identical with curve (d) from Fig. 4.

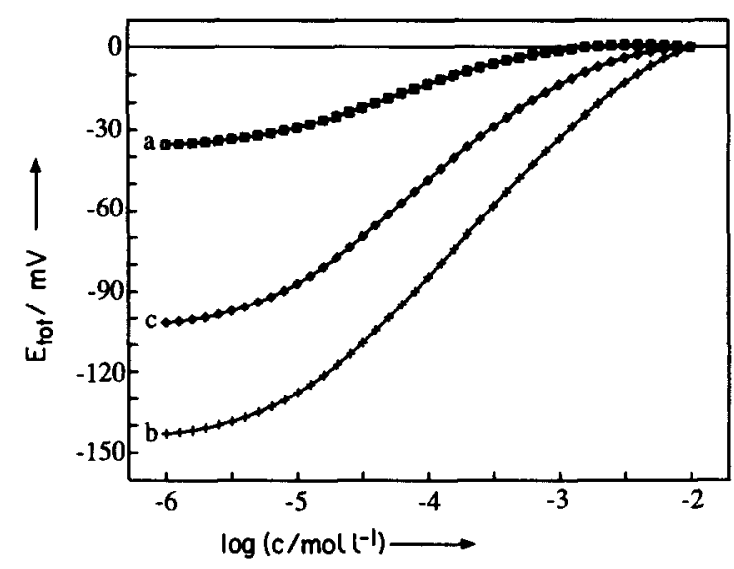

Fig. 7. The influence of ion-pair association in the membrane phase on the potentiometric response of divalent cations: (a) $\beta_{1}=10^{17}$ $1 \mathrm{~mol}^{-1}, \beta_{2}=10^{13} 1 \mathrm{~mol}^{-1}$, no association; (b) $K_{\mathrm{L}} \quad 1=K_{\mathrm{L}} \quad 2=10^{19}$ $1^{3} \mathrm{~mol}^{-3}$; (c) $K_{\mathrm{L}-\mathrm{Y} 1}=K_{\mathrm{L}-\mathrm{Y} 2}=10^{21} 1^{4} \mathrm{~mol}^{-4}$. Curve (a) is identical with curve (d) from Fig. 4.

pected to result in super-Nernstian slopes of either 52 $\left(K_{\mathrm{L}-}\right)$ or $42\left(K_{\mathrm{L}-\mathrm{Y}}\right) \mathrm{mV}$ per decade. A regular decrease in free cations $\left(c_{+1}^{\mathrm{m}}\right)$ in the membrane with an increase in sample cations $\left(c_{+1}\right)$ is responsible for these super-Nernstian slopes (appendix F).

Lindner et al. [14] have reported that a dioxamide based ionophore induces selectivity towards lead(II) ions in an ion-selective electrode. A selective and Nernstian response of around $60 \mathrm{mV}$ per decade was found for lead(II) ions in the presence of all interfering ions studied. Their explanation of this response of 60 $\mathrm{mV}$ per decade is that a monovalent lead species crosses the membrane / sample solution interface. However, this is only one of the possible explanations for the super-Nernstian behavior. Our model calculations reveal that an association between the lead-ionophore complex and sample anions in the membrane phase may also lead to an increased $(30 \rightarrow 60 \mathrm{mV})$ slope of the response. Our calix[4]arene ionophores 4 and 5 were incorporated in a PVC/BBPA (bis(butylpentyl)adipate) based CHEMFET. The polyHEMA hydrogel was conditioned in a lead(II) chloride solution (0.01 $\mathrm{M}+10^{-3} \mathrm{M} \mathrm{Mg}(\mathrm{OAc})_{2} / \mathrm{HCl} \mathrm{pH}$ 4). Both calix[4]arene ionophores 4 and 5 are selective for lead(II) ions with respect to calcium, cadmium, and copper [7]. Calix[4]arene 4 gave a slope of around 50 $\mathrm{mV}$ per decade as observed for other oxamide ionophores [14]. The other CHEMFETs based on calix[4larene 5 showed a response of $30 \mathrm{mV}$ per decade, as expected for a divalent cation. This difference in slope, nearly $60 \mathrm{mV}$ of calix[4]arene 4 and $30 \mathrm{mV}$ of calix[4]arene 5, implies a difference in complexation properties. It is possible that calix[4]arene 4 complexes a monovalent lead species because the rigidity of the 
calix[4]arene framework hinders complete encapsulation of the divalent lead cation by donor atoms. The more flcxible functional groups of calix[4]arcne 5 arc able to encapsulate the divalent lead cation completely.

\subsection{Diffusion potential}

A diffusion potential arises from a concentration gradient of charged species with different mobility in the membrane phase. Our group published [4] a model suggesting that a counteracting diffusion potential can be expected when an ionophore is covalently attached to the polymer membrane, but experimental proof has not yet been given for this theory. Model calculations [4] revealed that the magnitude of the product of the mobility and the concentration of a certain species determines its contribution to the diffusion potential. In general, lipophilic sample anions and cation-ionophore complexes are expected to provide a major contribution to the diffusion potential $[1,10,12,15]$. Therefore, a set of simulations was performed in which, at a given mobility of the sample anions in the membrane ( $u_{-}=10^{2}$, for other charged species $u=1$ ), the partition of the sample anion $k_{-}$and the magnitude of the association constants $\beta$ of the complexes between both the primary and interfering cations with the ionophore were investigated for monovalent cations. In order to obtain a maximum diffusion potential, the concentration of the cation in the inner electrolyte solution $c_{+, 1}$ (r) is lowered from $10^{-2}$ to $10^{-3} \mathrm{~mol}^{-1}$ and no interfering salt is present in the inner electrolyte solution.

In order to visualize the effect of the diffusion potential, the anion partition coefficient $k_{-}$was varied starting from the conditions given in Fig. 1(b). All calculated parameters of the outer boundary potential

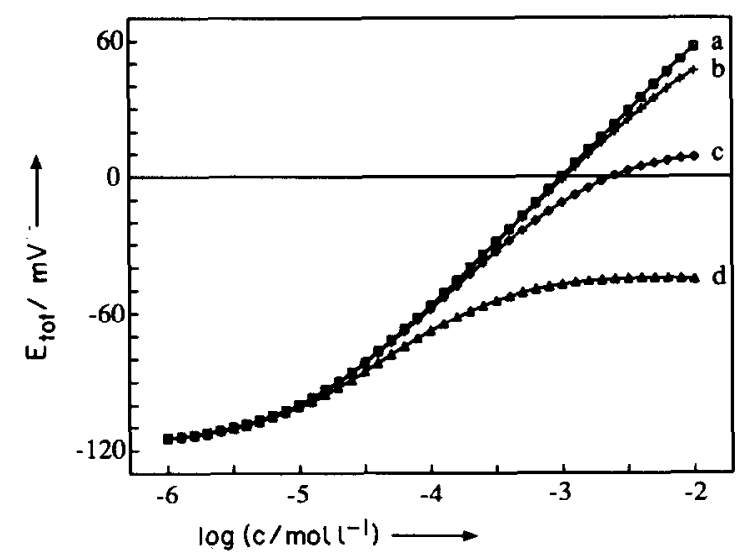

Fig. 8. The influence of the partition coefficient $k_{-}$on the diffusion potential and the potentiometric response of monovalent cations: (a) $k_{-}=10^{-6}, u_{-}=10^{2}$; (b) $k_{-}=10^{-5}$; (c) $k_{-}=10^{-4}$; (d) $k_{-}=10^{-3}$.
TABLE 2. Selectivity data of $\mathrm{Ag}^{+}$-selective CHEMFETs containing ionophore 5 with different plasticizers: $o$-NPOE, DOP, DOS

\begin{tabular}{llllll}
\hline Entry & Plasticizer & \multicolumn{2}{l}{ Interfering ion } & & \\
\cline { 3 - 6 } & & $\mathrm{Ca}\left(\mathrm{NO}_{3}\right)_{2}$ & $\mathrm{KNO}_{3}$ & $\mathrm{Cd}\left(\mathrm{NO}_{3}\right)_{2}$ & $\mathrm{Cu}\left(\mathrm{NO}_{3}\right)_{2}$ \\
\hline 1 & $o-\mathrm{NPOE}$ & -4.0 & -3.2 & -4.0 & -4.0 \\
& $($ slope $/ \mathrm{mV})$ & $(37)$ & $(39)$ & $(37)$ & $(37)$ \\
2 & DOP & -3.8 & -2.8 & -3.7 & -3.7 \\
& $($ (slope $/ \mathrm{mV})$ & $(50)$ & $(51)$ & $(49)$ & $(50)$ \\
3 & DOS & -3.4 & -2.9 & -3.3 & -3.5 \\
& (slope/mV) & $(57)$ & $(57)$ & $(59)$ & $(59)$ \\
\hline
\end{tabular}

$0.01 \mathrm{M}$ interfering salt concentration.

are identical (Appendix A Fig. 1(b) and Appendix G Fig. 8(a)). The only difference arises from the increase in the mobility of the sample anion $u_{-}$from 1 to $10^{2}$. At a sample cation concentration $c_{+1}(\mathrm{~s})$ of $10^{-2} \mathrm{~mol} \mathrm{l}^{-1}$ the product $u_{-} c_{-}^{\mathrm{m}}\left(7.3 \times 10^{-5} \mathrm{~mol} \mathrm{l}^{-1}\right.$, Appendix $\left.G\right)$ approaches the product $u c_{\mathrm{L}}^{\mathrm{m}} c_{+1}^{\mathrm{m}}\left(6.0 \times 10^{-4} \mathrm{~mol} \mathrm{l}^{-1}\right.$, Appendix $G$ ) which results in a small diffusion potential of $1.5 \mathrm{mV}$ (Appendix G). Therefore, Fig. 8(a) is nearly identical with Fig. 1(b). When the anion partition coefficient $k_{-}$is increased from $10^{-6}$ to $10^{-5}$, the effect of the diffusion potential at high primary cation concentration is more pronounced (Fig. 8(b)). A further increase in the anion partition coefficient to $10^{-4}$ (Fig. 8(c)) or $10^{-3}$ (Fig. 8(d)) changes the outer boundary potential, because at high primary cation concentration $\left(c_{+1}=10^{-2} \mathrm{~mol}^{-1}\right)$ the concentration of the sample anion in the membrane $c_{-}^{\mathrm{m}}$ is of the same order of magnitude as the concentration of the anionic sitc $c_{\mathrm{Y}}^{\mathrm{m}}$ (Appendix $\mathrm{G}$ ). The diffusion potential (at $c_{+1}(\mathrm{~s})=$ $\left.10^{-2} \mathrm{~mol}^{-1}\right)$ is increased from $1.5 \mathrm{mV}\left(k_{-}=10^{-6}\right.$, Fig. $8(\mathrm{a}))$ to $74.3 \mathrm{mV}\left(k_{-}=10^{-3}\right.$, Fig. 8(d)). In general the diffusion potential will be nearly zero in the case of a perfect Nernstian response (Fig. 8(a)). These simulations emphasize the importance of the exclusion of sample anions from the sensing membrane. Buck et al. [12] and Morf et al. [16] showed theoretically and experimentally that addition of tetraphenylborates as anionic sites to the membrane phase excludes sample anions and thus reduces the diffusion potential.

We decided to study the influence of the membrane composition, in particular of the plasticizer, on the potentiometric response because of the expected differences in partition coefficient $k_{-}$on the polarity of the membrane. For this purpose CHEMFETs were used with a PVC membrane deposited onto a polyHEMA hydrogel. The hydrogel was conditioned with 0.01 molar silver nitrate $\left(\mathrm{HNO}_{3}, \mathrm{pH} 4\right)$ prior to membrane deposition. A typical membrane consisted of 2 wt. $\%$ tetrasubstituted calix[4]arene $5,0.8 \mathrm{wt} . \%$ potassium tetrakis(4-chlorophenyl)borate as anionic site, 32.5 wt.\% PVC and 64.7 wt.\% plasticizer. In this study 


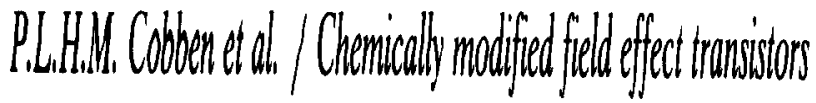

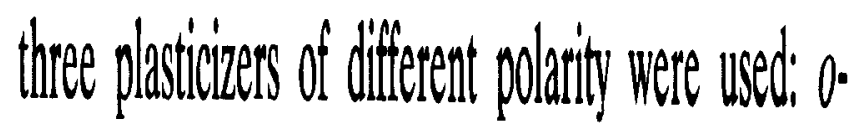
$\operatorname{PPOE}\left(\xi_{1}=24\right)[1], D O P\left(\varepsilon_{1}=52\right)[(18)$, and DOS $\left(\varepsilon_{1}, 3\right) \mid(18)$.

These three CHEMFETs were all selective towards silver in the presence of a number of interfering cations (Table 2). In all three cases the response resembles an S-curve. The interfering cation decreases the slope at low primary cation concentration, whereas the sample anions influence the slope at high primary cation concentration. A marked difference between the three different CHEMFETs is the slope of the response curves. The CHEMFET with the plasticizer of highest polarity (o-NPOE) (highest $k_{-}$compare Fig. 8) showed the lowest slope (37 $\mathrm{mV}$ per decade) in the linear response range. Decreasing the polarity of the plasticizer to DOP or even lower (DOS), raises the slope to $50 \mathrm{mV}$ per decade and $58 \mathrm{mV}$ per decade respectively. According to our membrane potential model, one (or a combination) of the three potentials, two boundary and a diffusion potential, may cause this effect. The inner boundary potential (membrane-polyHEMA hydrogel solution) can only change if during the measurement ions are transported through the hydrophobic sensing membrane and alter the concentration of ions in the polyHEMA hydrogel. Only a small amount of ions has to be transported to influence this potential because the volume of the hydrogel is small $(0.01 \mu 1)$.

After measurements with one CHEMFET, the DOP plasticized membranes were mounted in ISEs, which have a much larger inner compartment $(2 \mathrm{ml})$. The slopes of the response curves of the CHEMFET and this ISE were identical within experimental error $(50 \pm$ $1 \mathrm{mV}$ ). This indicates that the inner boundary potential is stable during the whole measurement of the CHEMFET. So only the outer boundary and the diffusion potential can be responsible for the above described effects.

The beginning of anion response at high primary cation concentration, according to the model calculations, can be caused by the outer boundary potential (membrane-sample solution). The association constant $\beta_{1}$ of the complex formed between the primary cation and the ionophore should be extremely high $\left(\beta_{1}=10^{13}\right.$ $1 \mathrm{~mol}^{-1}$, see Fig. 1(d)) to cause such an effect. The point of zero slope was found to be in all three experiments within a narrow range of primary cation concentration $\left(\log c_{+1}=-1.9\right.$ to -2.2$)$.

Another explanation for the lowered slope of these response curves is a diffusion potential. It is not yet

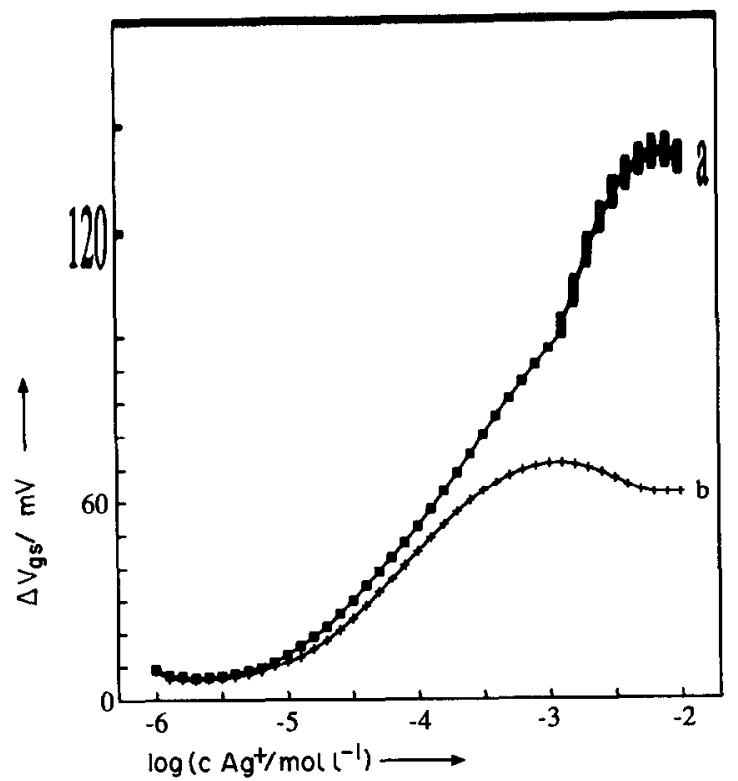

Fig. 9. $\mathrm{Ag}^{+}$response of CHEMFETs containing ionophore 2 in (a) $0.1 \mathrm{M} \mathrm{KNO}_{3}$, (b) $1 \mathrm{M} \mathrm{KNO}_{3}$.

We have studied experimentally the influence of interfering salt concentration of an $\mathrm{Ag}^{+}$-selective CHEMFET containing ionophore 2 with potassium nitrate as the interfering salt. When the concentration of the potassium nitrate was increased from 0.01 to 0.1 or $1 \mathrm{M}$ the slope of the response curve was lowered from $57(0.01 \mathrm{M})$ to $54(0.1 \mathrm{M})$, or $41(1 \mathrm{M}) \mathrm{mV}$ per decade $^{-1}$ (Fig. 9). In $1 \mathrm{M} \mathrm{KNO}_{3}$ not only the slope is lower but also some anion response is observed. At high silver cation concentration the sensing membrane loses its ability to induce either cation or anion response because salt extraction $\left(\mathrm{AgNO}_{3}\right)$ takes place. In our model calculations these effects can be simulated only by a change in (outer) boundary potential. Superposed on this potential, a diffusion potential might be present but experimental proof is lacking.

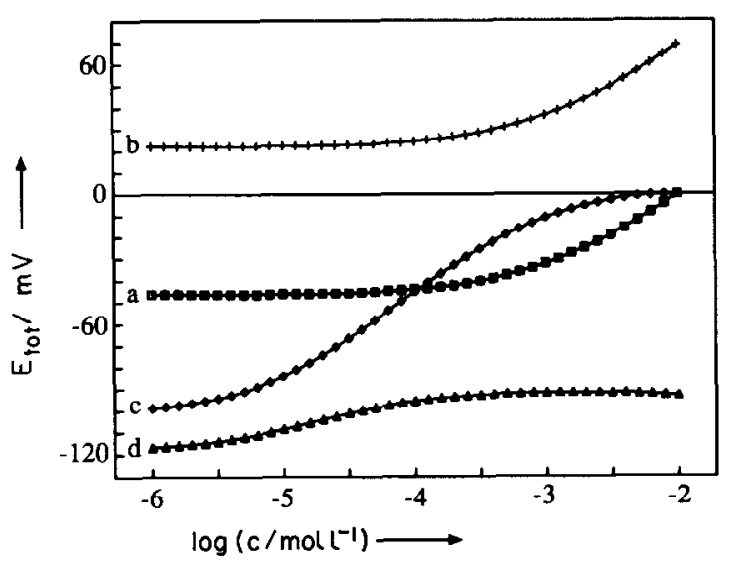


The influence of the magnitude of the association constants $\beta$ of the complexes between both the primary and the interfering cations with the ionophore was studied starting from the conditions of Fig. 8(a). If the absolute value of the association constant is lowered $\left(\beta_{1}=10^{5} \mathrm{l} \mathrm{mol}^{-1}, \beta_{2}=101 \mathrm{~mol}^{-1}\right.$, see Fig. $10(\mathrm{~b})$ ), the diffusion potential is reduced. The lower diffusion potential is due to the lower concentration of sample anions $c_{-}^{\mathrm{m}}$ in the membrane (Appendix $\mathrm{H}$ ) compared with the case in which the association constant is higher (Fig. 8(a)), Appendix G). Therefore, the overall membrane potential will be similar (Fig. 10(a) (the same as Fig. 1(c)) and Fig. 10(b)), whether $u_{-}$is 1 or $10^{2}$.

When the association constant is increased $\left(\beta_{1}=\right.$ $10^{13} 1 \mathrm{~mol}^{-1}, \beta_{2}=10^{9} 1 \mathrm{~mol}^{-1}$, see Fig. $10(\mathrm{~d})$ ), the theoretically expected response is nearly constant. The outer boundary potential already causes a sub-Nernstian slope ( $43 \mathrm{mV}$ per decade ${ }^{-1}$, Fig. 10(c) (the same as Fig. 1(d))) (vide supra). The diffusion potential further diminishes the response (Fig. 10(d) and Appendix H).

\section{Conclusions}

A model has been developed for the calculation of the potential of a membrane which is placed between a sample solution and a reference solution. This model is a further extension of a theoretical description presented previously by our group [4] and can also account for divalent cations and ion-pair association in the system. Calculations of the membrane potential according to this model revealed several general phenomena which have been observed experimentally. For a Nernstian response of the sensor the value of the association between an ionophore and a cation in the membrane should be in a restricted range. Theoretically, ion-pair association within the membrane phase in general reduces the slope of the response curves of monovalent cations. In the case of divalent cations an ion-pair association in the membrane in which sample anions are involved could lead to a super-Nernstian response. A diffusion potential is expected when the product of mobility and concentration of free sample anions in the membrane is of the same order of magnitude as the product of mobility and the concentration of cation-ionophore complexes. In general the exclusion of sample anions from the membrane is important in order to obtain a Nernstian response of the sensor.

\section{References and notes}

1 W.E. Morf, The Principles of Ion-Selective Electrodes and Membrane Transport, Elsevier, Amsterdam, 1981.

2 T. Teorell, Proc. Soc. Exp. Biol. Med., 33 (1935) 282.

3 K.H. Meyer and J.F. Sievers, Helv. Chim. Acta, 19 (1936) 649.

4 A. van den Berg, P.D. van der Wal, M. Skowronska-Ptasinska, E.J.R. Sudhölter, P. Bergveld and D.N. Reinhoudt, J. Electroanal. Chem., 284 (1990) 1.

5 R.D. Armstrong, Electrochim. Acta, 32 (1987) 1549.

6 P.L.H.M. Cobben, R.J.M. Egberink, J.G. Bomer, J.R. Haak, P. Bergveld and D.N. Reinhoudt, Sens. Actuators B, 6 (1992) 304.

7 P.L.H.M. Cobben, R.J.M. Egberink, J.G. Bomer, P. Bergveld, W. Verboom and D.N. Reinhoudt, J. Am. Chem. Soc., 114 (1992) 10573.

8 IUPAC Recomendations for Nomenclature of Ion-Selective Electrodes, Pure Appl. Chem., 48 (1976) 127.

9 P.C. Meier, Anal. Chim. Acta, 136 (1982) 363.

10 R. Eugster, P.M. Gehrig, W.E. Morf, U.E. Spichiger and W. Simon, Anal. Chem., 63 (1991) 2285.

11 P.D. van der Wal, E.J.R. Sudhölter and D.N. Reinhoudt, Anal. Chim. Acta, 245 (1991) 159.

12 R.P. Buck, K. Toth, E. Graf, G. Horvai and E. Pungor, J. Electroanal. Chem., 223 (1987) 51.

13 W.F. Nijenhuis, E.G. Buitenhuis, F. de Jong, E.J.R. Sudhölter and D.N. Reinhoudt, J. Am. Chem. Soc., 113 (1991) 7963.

14 E. Lindner, K. Toth, E. Pungor, F. Behm, P. Oggenfuss, D.H. Welti, D. Ammann, W.E. Morf, E. Pretsch and W. Simon, Anal. Chem., 56 (1984) 1127.

15 J. Koryta and K. Stulik, Ion-Selective Electrodes, Cambridge University Press, Cambridge, 1983, 2nd edn.

H. Freiser (Ed.), Ion-Selective Electrodes in Analytical Chemistry, Vol. 1, Plenum, New York, 1978.

16 W.E. Morf, G. Kahr and W. Simon, Anal. Lett., 7 (1974) 9.

17 O. Ryba and J. Petranek, Coll. Czech., Chem. Commun., 49 (1984) 2371.

18 Mark, Bikales, Overberger and Menges (Eds), Polymer Encyclopedia, Wiley, New York, 1989, p. 570.

19 W. Simon, Anal. Lett., 7 (1974) 9.

20 J.H. Boles and R.P. Buck. Anal. Chem., 45 (1973) 2057.

21 M.-T. Lai and J.-S. Shih, Analyst, 111 (1986) 891.

\section{Appendix A}

The influence of the association constant $\beta$ on the potentiometric response of monovalent cations. Starting parameters, $L_{\text {tot }}=1 \times 10^{-3} \mathrm{~mol} \mathrm{l}^{-1}, Y_{\text {tot }}=6 \times$

$10^{-4} \mathrm{~mol} \mathrm{l}^{-1}, k_{+1}=k_{+2}=k_{-}=1 \times 10^{-6}, c_{+1}(\mathrm{r})=1 \times$ $10^{-2} \mathrm{~mol} \mathrm{l}^{-1}, \beta_{1}=1 \times 10^{9} 1 \mathrm{~mol}^{-1}$. All values of $c$ are given in moles per liter. 
Fig. 1(a)

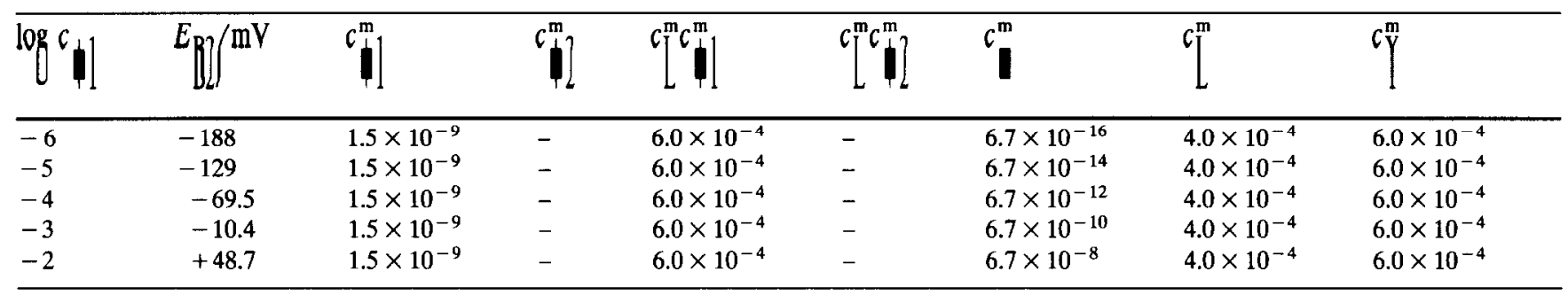

Fig. 1(b), parameters as 1(a) and $c_{+2}=1 \times 10^{-1} \mathrm{~mol} \mathrm{l}^{-1}, \beta_{2}=1 \times 10^{5} \mathrm{Imol}^{-1}$

\begin{tabular}{lllllllll}
\hline $\log c_{+1}$ & $E_{\mathrm{B} 2} / \mathrm{mV}$ & $c_{+1}^{\mathrm{m}}$ & $c_{+2}^{\mathrm{m}}$ & $c_{\mathrm{L}}^{\mathrm{m}} c_{+1}^{\mathrm{m}}$ & $c_{\mathrm{L}}^{\mathrm{m}} c_{+2}^{\mathrm{m}}$ & $c_{-}^{\mathrm{m}}$ & $c_{\mathrm{L}}^{\mathrm{m}}$ \\
\hline-6 & -125 & $1.3 \times 10^{-10}$ & $1.1 \times 10^{-5}$ & $1.1 \times 10^{-4}$ & $4.7 \times 10^{-4}$ & $7.7 \times 10^{-10}$ & $4.1 \times 10^{-4}$ & $6.0 \times 10^{-4}$ \\
-5 & -110 & $7.3 \times 10^{-10}$ & $7.3 \times 10^{-6}$ & $3.0 \times 10^{-4}$ & $3.0 \times 10^{-4}$ & $1.4 \times 10^{-9}$ & $4.1 \times 10^{-4}$ & $6.0 \times 10^{-4}$ \\
-4 & -66.9 & $1.4 \times 10^{-9}$ & $1.4 \times 10^{-6}$ & $5.4 \times 10^{-4}$ & $5.4 \times 10^{-5}$ & $7.4 \times 10^{-9}$ & $4.0 \times 10^{-4}$ & $6.0 \times 10^{-4}$ \\
-3 & -10.1 & $1.5 \times 10^{-9}$ & $1.5 \times 10^{-7}$ & $5.9 \times 10^{-4}$ & $5.9 \times 10^{-6}$ & $6.8 \times 10^{-8}$ & $4.0 \times 10^{-4}$ & $6.0 \times 10^{-4}$ \\
-2 & +48.7 & $1.5 \times 10^{-9}$ & $1.5 \times 10^{-8}$ & $6.0 \times 10^{-4}$ & $6.0 \times 10^{-7}$ & $7.3 \times 10^{-7}$ & $4.0 \times 10^{-4}$ & $6.0 \times 10^{-4}$ \\
\hline
\end{tabular}

Fig. 1(c), parameters as 1(a) and $c_{+2}=1 \times 10^{-1} \mathrm{~mol} \mathrm{l}^{-1}, \beta_{1}=1 \times 10^{5} 1 \mathrm{~mol}^{-1}, \beta_{2}=101 \mathrm{~mol}^{-1}$

\begin{tabular}{lllllllll}
\hline $\log c_{+1}$ & $E_{\mathrm{B} 2} / \mathrm{mV}$ & $c_{+1}^{\mathrm{m}}$ & $c_{+2}^{\mathrm{m}}$ & $c_{\mathrm{L}}^{\mathrm{m}} c_{+1}^{\mathrm{m}}$ & $c_{\mathrm{L}}^{\mathrm{m}} c_{+2}^{\mathrm{m}}$ & $c_{-}^{\mathrm{m}}$ & $c_{\mathrm{L}}^{\mathrm{m}}$ & $c_{\mathrm{Y}}^{\mathrm{m}}$ \\
\hline-6 & -223 & $5.9 \times 10^{-9}$ & $5.9 \times 10^{-4}$ & $5.9 \times 10^{-7}$ & $5.9 \times 10^{-6}$ & $1.7 \times 10^{-11}$ & $9.9 \times 10^{-4}$ & $6.0 \times 10^{-4}$ \\
-5 & -223 & $5.9 \times 10^{-8}$ & $5.9 \times 10^{-4}$ & $5.8 \times 10^{-6}$ & $5.8 \times 10^{-6}$ & $1.7 \times 10^{-11}$ & $9.9 \times 10^{-4}$ & $6.0 \times 10^{-4}$ \\
-4 & -221 & $5.4 \times 10^{-7}$ & $5.4 \times 10^{-4}$ & $5.1 \times 10^{-5}$ & $5.1 \times 10^{-6}$ & $1.8 \times 10^{-11}$ & $9.4 \times 10^{-4}$ & $6.0 \times 10^{-4}$ \\
-3 & -209 & $4.4 \times 10^{-6}$ & $3.4 \times 10^{-4}$ & $2.5 \times 10^{-4}$ & $2.5 \times 10^{-6}$ & $3.0 \times 10^{-11}$ & $7.4 \times 10^{-4}$ & $6.0 \times 10^{-4}$ \\
-2 & -177 & $9.7 \times 10^{-6}$ & $9.7 \times 10^{-5}$ & $4.9 \times 10^{-4}$ & $4.9 \times 10^{-7}$ & $1.1 \times 10^{-10}$ & $5.1 \times 10^{-4}$ & $6.0 \times 10^{-4}$ \\
\hline
\end{tabular}

Fig. 1(d), parameters as 1(a) and $c_{+2}=1 \times 10^{-1} \mathrm{~mol} \mathrm{l}^{-1}, \beta_{1}=1 \times 10^{13} 1 \mathrm{~mol}^{-1}, \beta_{2}=1 \times 10^{9} \mathrm{Imol}^{-1}$

\begin{tabular}{lllllllll}
\hline $\log c_{+1}$ & $E_{\mathrm{B} 2} / \mathrm{mV}$ & $c_{+1}^{\mathrm{m}}$ & $c_{+2}^{\mathrm{m}}$ & $c_{\mathrm{L}}^{\mathrm{m}} c_{+1}^{\mathrm{m}}$ & $c_{\mathrm{L}}^{\mathrm{m}} c_{+2}^{\mathrm{m}}$ & $c_{-}^{\mathrm{m}}$ & $c_{\mathrm{L}}^{\mathrm{m}}$ & $c_{\mathrm{Y}}^{\mathrm{m}}$ \\
\hline-6 & +110 & $1.4 \times 10^{-14}$ & $1.4 \times 10^{-9}$ & $5.5 \times 10^{-5}$ & $5.5 \times 10^{-4}$ & $7.1 \times 10^{-6}$ & $3.9 \times 10^{-4}$ & $6.0 \times 10^{-4}$ \\
-5 & +124 & $7.9 \times 10^{-14}$ & $7.9 \times 10^{-10}$ & $3.1 \times 10^{-4}$ & $3.1 \times 10^{-4}$ & $1.3 \times 10^{-5}$ & $3.9 \times 10^{-4}$ & $6.0 \times 10^{-4}$ \\
-4 & +163 & $1.7 \times 10^{-13}$ & $1.7 \times 10^{-10}$ & $6.0 \times 10^{-4}$ & $6.0 \times 10^{-5}$ & $5.7 \times 10^{-5}$ & $3.4 \times 10^{-4}$ & $6.0 \times 10^{-4}$ \\
-3 & +198 & $4.6 \times 10^{-13}$ & $4.6 \times 10^{11}$ & $8.1 \times 10^{4}$ & $8.1 \times 10^{6}$ & $2.2 \times 10^{4}$ & $1.8 \times 10^{4}$ & $6.0 \times 10^{-4}$ \\
-2 & +208 & $3.0 \times 10^{-12}$ & $3.0 \times 10^{-11}$ & $9.7 \times 10^{-4}$ & $9.7 \times 10^{-7}$ & $3.7 \times 10^{-4}$ & $3.2 \times 10^{-5}$ & $6.0 \times 10^{-4}$ \\
\hline
\end{tabular}

\section{Appendix B}

The influence of association in the membrane phase on the potentiometric response of monovalent cations. Starting parameters, $L_{\text {tot }}=1 \times 10^{-3} \mathrm{~mol} \mathrm{l}^{-1}, Y_{\text {tot }}=6$ $\times 10^{-4} \mathrm{~mol} \mathrm{l}^{-1}, k_{+1}=k_{+2}=k_{-}=1 \times 10^{-6}, c_{+1}(\mathrm{r})=1$

Fig. 3(a)

\begin{tabular}{lllllllll}
\hline $\log c_{+1}$ & $E_{\mathrm{B} 2} / \mathrm{mV}$ & $c_{+1}^{\mathrm{m}}$ & $c_{+2}^{\mathrm{m}}$ & $c_{\mathrm{L}}^{\mathrm{m}} c_{+1}^{\mathrm{m}}$ & $c^{\mathrm{L}} c_{+2}^{\mathrm{m}}$ & $c_{-}^{\mathrm{m}}$ & $c_{\mathrm{L}}^{\mathrm{m}}$ & $c_{\mathrm{Y}}^{\mathrm{m}}$ \\
\hline-6 & +110 & $1.4 \times 10^{-14}$ & $1.4 \times 10^{-9}$ & $5.5 \times 10^{-5}$ & $5.5 \times 10^{-4}$ & $7.1 \times 10^{-6}$ & $3.9 \times 10^{-4}$ & $6.0 \times 10^{-4}$ \\
-5 & +124 & $7.9 \times 10^{-14}$ & $7.9 \times 10^{-10}$ & $3.1 \times 10^{-4}$ & $3.1 \times 10^{-4}$ & $1.3 \times 10^{-5}$ & $3.9 \times 10^{-4}$ & $6.0 \times 10^{-4}$ \\
-4 & +163 & $1.7 \times 10^{-13}$ & $1.7 \times 10^{-10}$ & $6.0 \times 10^{-4}$ & $6.0 \times 10^{-5}$ & $5.7 \times 10^{-5}$ & $3.4 \times 10^{-4}$ & $6.0 \times 10^{-4}$ \\
-3 & +198 & $4.6 \times 10^{-13}$ & $4.6 \times 10^{-11}$ & $8.1 \times 10^{-4}$ & $8.1 \times 10^{-6}$ & $2.2 \times 10^{-4}$ & $1.8 \times 10^{-4}$ & $6.0 \times 10^{-4}$ \\
-2 & +208 & $3.0 \times 10^{-12}$ & $3.0 \times 10^{-11}$ & $9.7 \times 10^{-4}$ & $9.7 \times 10^{-7}$ & $3.7 \times 10^{-4}$ & $3.2 \times 10^{-5}$ & $6.0 \times 10^{-4}$ \\
\hline
\end{tabular}

Fig. 3(b), parameters as 3(a) and $K_{\mathrm{Y}_{21}}=K_{\mathrm{Yz}_{2}}=1 \times 10^{15} 1 \mathrm{~mol}^{-1}$

\begin{tabular}{|c|c|c|c|c|c|c|c|c|c|c|}
\hline $\log c_{+1}$ & $E_{\mathrm{B} 2} / \mathrm{mV}$ & $c_{+1}^{\mathrm{m}}$ & $c_{+2}^{\mathrm{m}}$ & $c_{\mathrm{L}}^{\mathrm{m}} c_{+1}^{\mathrm{m}}$ & $c_{\mathrm{L}}^{\mathrm{m}} c_{+2}^{\mathrm{m}}$ & $c_{-}^{\mathbf{m}}$ & $c_{\mathbf{L}}^{\mathrm{m}}$ & $c_{\mathrm{Y}}^{\mathrm{m}}$ & $c_{1}^{\mathrm{m}}\left(c_{\mathrm{Y}}^{\mathrm{m}}\right)_{\mathrm{z}}$ & $\begin{array}{l}c_{M}^{m}\left(c_{\mathrm{Y}}^{\mathrm{m}}\right)_{\mathrm{z}} \\
2\end{array}$ \\
\hline-6 & +177 & $1.0 \times 10^{-15}$ & $1.0 \times 10^{-10}$ & $9.1 \times 10^{-6}$ & $9.1 \times 10^{-5}$ & $1.0 \times 10^{-4}$ & $9.0 \times 10^{-4}$ & $6.0 \times 10^{-9}$ & $6.0 \times 10^{-9}$ & $6.0 \times 10^{-4}$ \\
\hline-5 & +184 & $7.6 \times 10^{-15}$ & $7.6 \times 10^{-11}$ & $6.6 \times 10^{-5}$ & $6.6 \times 10^{-5}$ & $1.3 \times 10^{-4}$ & $8.7 \times 10^{-4}$ & $7.9 \times 10^{-9}$ & $6.0 \times 10^{-8}$ & $6.0 \times 10^{-4}$ \\
\hline-4 & +204 & $3.6 \times 10^{-14}$ & $3.6 \times 10^{-11}$ & $2.6 \times 10^{-4}$ & $2.6 \times 10^{-5}$ & $2.8 \times 10^{-4}$ & $7.2 \times 10^{-4}$ & $1.7 \times 10^{-8}$ & $6.0 \times 10^{-7}$ & $6.0 \times 10^{-4}$ \\
\hline-3 & +224 & $1.6 \times 10^{-13}$ & $1.6 \times 10^{-11}$ & $6.2 \times 10^{-4}$ & $6.2 \times 10^{-6}$ & $6.2 \times 10^{-4}$ & $3.8 \times 10^{-4}$ & $3.7 \times 10^{-8}$ & $5.9 \times 10^{-6}$ & $5.9 \times 10^{-4}$ \\
\hline-2 & +232 & $1.2 \times 10^{-12}$ & $1.2 \times 10^{-11}$ & $9.2 \times 10^{-4}$ & $9.2 \times 10^{-7}$ & $9.2 \times 10^{-4}$ & $7.7 \times 10^{-5}$ & $4.6 \times 10^{-8}$ & $5.5 \times 10^{-5}$ & $5.5 \times 10^{-4}$ \\
\hline
\end{tabular}

$\times 10^{-2} \mathrm{~mol} \mathrm{l}^{-1}, \beta_{1}=1 \times 10^{13} 1 \mathrm{~mol}^{-1}, \beta_{2}=1 \times 10^{9}$ $1 \mathrm{~mol}^{-1}, c_{+2}=1 \times 10^{-1} \mathrm{~mol} \mathrm{l}{ }^{-1}$. All values of $c$ are given in moles per liter. 
Fig. 3(c), parameters as 3(a) and $K_{\mathrm{LYz} 1}=K_{\mathrm{LYz} 2}=1 \times 10^{17} 1^{2} \mathrm{~mol}^{-2}$

\begin{tabular}{|c|c|c|c|c|c|c|c|c|c|c|}
\hline $\log c_{+1}$ & $E_{\mathrm{B} 2} / \mathrm{mV}$ & $c_{+1}^{\mathrm{m}}$ & $c_{+2}^{m}$ & $c_{\mathrm{L}}^{\mathrm{m}} c_{+1}^{\mathrm{m}}$ & $c_{\mathrm{L}}^{\mathrm{m}} c_{+2}^{\mathrm{m}}$ & $c_{-}^{\mathbf{m}}$ & $c_{\mathrm{L}}^{\mathrm{m}}$ & $c_{\mathrm{Y}}^{\mathrm{m}}$ & $c_{\mathrm{M}}^{\mathrm{m}} c_{\mathrm{L}}^{\mathrm{m}}\left(c_{\mathrm{Y}}^{\mathrm{m}}\right)_{\mathrm{z} 1}$ & $c_{\mathrm{M}}^{\mathrm{m}} c_{\mathrm{L}}^{\mathrm{m}}\left(c_{\mathrm{Y}}^{\mathrm{m}}\right)_{\mathrm{z} 2}$ \\
\hline-6 & +165 & $1.6 \times 10^{-15}$ & $1.6 \times 10^{-10}$ & $5.6 \times 10^{-6}$ & $5.6 \times 10^{-5}$ & $6.1 \times 10^{-5}$ & $3.4 \times 10^{-4}$ & $1.1 \times 10^{-7}$ & $6.0 \times 10^{-9}$ & $6.0 \times 10^{-4}$ \\
\hline-5 & +172 & $1.3 \times 10^{-14}$ & $1.3 \times 10^{-10}$ & $4.0 \times 10^{-5}$ & $4.0 \times 10^{-5}$ & $8.0 \times 10^{-5}$ & $3.2 \times 10^{-4}$ & $1.5 \times 10^{-7}$ & $6.0 \times 10^{-8}$ & $6.0 \times 10^{-4}$ \\
\hline-4 & +190 & $6.2 \times 10^{-14}$ & $6.2 \times 10^{-11}$ & $1.5 \times 10^{-4}$ & $1.5 \times 10^{-5}$ & $1.6 \times 10^{-4}$ & $2.4 \times 10^{-4}$ & $4.1 \times 10^{-7}$ & $6.0 \times 10^{-7}$ & $6.0 \times 10^{-4}$ \\
\hline-3 & +206 & $3.3 \times 10^{-13}$ & $3.3 \times 10^{-11}$ & $3.1 \times 10^{-4}$ & $3.1 \times 10^{-6}$ & $3.1 \times 10^{-4}$ & $9.3 \times 10^{-5}$ & $1.9 \times 10^{-6}$ & $5.9 \times 10^{-6}$ & $5.9 \times 10^{-4}$ \\
\hline-2 & +210 & $2.9 \times 10^{-12}$ & $2.9 \times 10^{-11}$ & $4.0 \times 10^{-4}$ & $4.0 \times 10^{-7}$ & $3.9 \times 10^{-4}$ & $1.4 \times 10^{-5}$ & $1.3 \times 10^{-5}$ & $5.3 \times 10^{-5}$ & $5.3 \times 10^{-4}$ \\
\hline
\end{tabular}

Fig. 3(d), parameters as 3(a) and $K_{\mathrm{L}-\mathrm{z} 1}=K_{\mathrm{L}-\mathrm{z} 2}=1 \times 10^{17} \mathrm{1}^{2} \mathrm{~mol}^{-2}$

\begin{tabular}{|c|c|c|c|c|c|c|c|c|c|c|}
\hline $\log c_{+1}$ & $E_{\mathrm{B} 2} / \mathrm{mV}$ & $c_{+1}^{m}$ & $c_{+2}^{\mathbf{m}}$ & $c_{\mathrm{L}}^{\mathrm{m}} c_{+1}^{\mathrm{m}}$ & $c_{\mathrm{L}}^{\mathrm{m}} c_{+2}^{\mathrm{m}}$ & $c_{-}^{\mathbf{m}}$ & $c_{\mathrm{L}}^{\mathrm{m}}$ & $c_{\mathbf{Y}}^{\mathrm{m}}$ & $c_{\mathrm{M}}^{\mathrm{m}} c_{\mathrm{L}}^{\mathrm{m}}\left(c_{-}^{\mathrm{m}}\right)_{\mathrm{z} 1}$ & $c_{\mathrm{M}}^{\mathrm{m}} c_{\mathrm{L}}^{\mathrm{m}}\left(c_{-}^{\mathrm{m}}\right)_{\mathrm{z} 2}$ \\
\hline-6 & -67.0 & $1.4 \times 10^{-11}$ & $1.4 \times 10^{-6}$ & $5.4 \times 10^{-5}$ & $5.4 \times 10^{-4}$ & $7.4 \times 10^{-9}$ & $4.0 \times 10^{-7}$ & $6.0 \times 10^{-4}$ & $4.0 \times 10^{-9}$ & $4.0 \times 10^{-4}$ \\
\hline-5 & -51.7 & $7.5 \times 10^{-11}$ & $7.5 \times 10^{-7}$ & $3.0 \times 10^{-4}$ & $3.0 \times 10^{-4}$ & $1.3 \times 10^{-8}$ & $4.0 \times 10^{-7}$ & $6.0 \times 10^{-4}$ & $4.0 \times 10^{-8}$ & $4.0 \times 10^{-4}$ \\
\hline-4 & -8.0 & $1.4 \times 10^{-10}$ & $1.4 \times 10^{-7}$ & $5.5 \times 10^{-4}$ & $5.5 \times 10^{-5}$ & $7.3 \times 10^{-8}$ & $4.0 \times 10^{-7}$ & $6.0 \times 10^{-4}$ & $4.0 \times 10^{-7}$ & $4.0 \times 10^{-4}$ \\
\hline-3 & +48.4 & $1.5 \times 10^{-10}$ & $1.5 \times 10^{-8}$ & $6.0 \times 10^{-4}$ & $6.0 \times 10^{-6}$ & $6.6 \times 10^{-7}$ & $3.9 \times 10^{-7}$ & $6.0 \times 10^{4}$ & $4.0 \times 10^{-6}$ & $4.0 \times 10^{-4}$ \\
\hline-2 & +102 & $1.9 \times 10^{-10}$ & $1.9 \times 10^{-9}$ & $6.1 \times 10^{-4}$ & $6.1 \times 10^{-7}$ & $5.9 \times 10^{-6}$ & $3.3 \times 10^{-7}$ & $6.0 \times 10^{-4}$ & $3.6 \times 10^{-5}$ & $3.6 \times 10^{-3}$ \\
\hline
\end{tabular}

\section{Appendix $\mathrm{C}$}

The influence of the association constant $\beta$ on the potentiometric response of divalent cations. Starting parameters, $L_{\text {tot }}=1 \times 10^{-3} \mathrm{~mol} \mathrm{l}^{-1}, Y_{\text {tot }}=1.6 \times 10^{-3}$ $\operatorname{mol~1} 1^{-1}, k_{+1}=k_{+2}=k_{-}=1 \times 10^{-6}, c_{+1}(\mathrm{r})=1 \times 10^{-2}$ mol $1^{-1}, \beta_{1}=1 \times 10^{9} 1 \mathrm{~mol}^{-1}$. All values of $c$ are given in moles per liter.

Fig. 4(a)

\begin{tabular}{lllllllll}
\hline $\log c_{+1}$ & $E_{\mathrm{B} 2} / \mathrm{mV}$ & $c_{+1}^{\mathrm{m}}$ & $c_{+2}^{\mathrm{m}}$ & $c_{\mathrm{L}}^{\mathrm{m}} c_{+1}^{\mathrm{m}}$ & $c_{\mathrm{L}}^{\mathrm{m}} c_{+2}^{\mathrm{m}}$ & $c_{-}^{\mathrm{m}}$ & $c_{\mathrm{L}}^{\mathrm{m}}$ & $c_{\mathrm{Y}}^{\mathrm{m}}$ \\
\hline-6 & -106 & $4.0 \times 10^{-9}$ & - & $8.0 \times 10^{-4}$ & - & $3.2 \times 10^{-14}$ & $2.0 \times 10^{-4}$ & $1.6 \times 10^{-3}$ \\
-5 & -76.9 & $4.0 \times 10^{-9}$ & - & $8.0 \times 10^{-4}$ & - & $1.0 \times 10^{-12}$ & $2.0 \times 10^{-4}$ & $1.6 \times 10^{-3}$ \\
-4 & -47.4 & $4.0 \times 10^{-9}$ & - & $8.0 \times 10^{-4}$ & - & $3.2 \times 10^{-11}$ & $2.0 \times 10^{-4}$ & $1.6 \times 10^{-3}$ \\
-3 & -17.8 & $4.0 \times 10^{-9}$ & - & $8.0 \times 10^{-4}$ & - & $1.0 \times 10^{-9}$ & $2.0 \times 10^{-4}$ & $1.6 \times 10^{-3}$ \\
-2 & +11.8 & $4.0 \times 10^{-9}$ & - & $8.0 \times 10^{-4}$ & - & $3.2 \times 10^{-8}$ & $2.0 \times 10^{-4}$ & $1.6 \times 10^{-3}$ \\
\hline
\end{tabular}

Fig. 4(b), parameters as $4(\mathrm{a})$ and $c_{+2}=1 \times 10^{-1} \mathrm{~mol} \mathrm{l}^{-1}, \beta_{2}=1 \times 10^{-5} 1 \mathrm{~mol}^{-1}$

\begin{tabular}{lllllllll}
\hline $\log c_{+1}$ & $E_{\mathrm{B} 2} / \mathrm{mV}$ & $c_{+1}^{\mathrm{m}}$ & $c_{+2}^{\mathrm{m}}$ & $c_{\mathrm{L}}^{\mathrm{m}} c_{+1}^{\mathrm{m}}$ & $c_{\mathbf{L}}^{\mathrm{m}} c_{+2}^{\mathrm{m}}$ & $c_{-}^{\mathrm{m}}$ & $c_{\mathrm{L}}^{\mathrm{m}}$ & $c_{\mathrm{Y}}^{\mathrm{m}}$ \\
\hline-6 & -73.4 & $3.0 \times 10^{-10}$ & $3.1 \times 10^{-5}$ & $7.0 \times 10^{5}$ & $7.0 \times 10^{-4}$ & $1.2 \times 10^{-8}$ & $2.3 \times 10^{-4}$ & $1.6 \times 10^{-3}$ \\
-5 & -66.6 & $1.8 \times 10^{-9}$ & $1.8 \times 10^{-5}$ & $3.9 \times 10^{-4}$ & $3.9 \times 10^{-4}$ & $1.5 \times 10^{-8}$ & $2.2 \times 10^{-4}$ & $1.6 \times 10^{-3}$ \\
-4 & -45.9 & $3.6 \times 10^{-9}$ & $3.6 \times 10^{-6}$ & $7.2 \times 10^{-4}$ & $7.2 \times 10^{-5}$ & $3.4 \times 10^{-8}$ & $2.0 \times 10^{-4}$ & $1.6 \times 10^{-3}$ \\
-3 & -17.6 & $4.0 \times 10^{-9}$ & $4.0 \times 10^{-7}$ & $7.9 \times 10^{-4}$ & $7.9 \times 10^{-6}$ & $1.0 \times 10^{-7}$ & $2.0 \times 10^{-4}$ & $1.6 \times 10^{-3}$ \\
-2 & +11.8 & $4.0 \times 10^{-9}$ & $4.0 \times 10^{-8}$ & $8.0 \times 10^{-4}$ & $8.0 \times 10^{-7}$ & $3.5 \times 10^{-7}$ & $2.0 \times 10^{-4}$ & $1.6 \times 10^{-3}$ \\
\hline
\end{tabular}

Fig. 4(c), parameters as $4(\mathrm{a})$ and $c_{+2}=1 \times 10^{-1} \mathrm{~mol} \mathrm{l}^{-1}, \beta_{1}=1 \times 10^{5} 1 \mathrm{~mol}^{-1}, \beta_{2}=101 \mathrm{~mol}^{-1}$

\begin{tabular}{lllllllll}
\hline $\log c_{+1}$ & $E_{\mathrm{B} 2} / \mathrm{mV}$ & $c_{+1}^{\mathrm{m}}$ & $c_{+2}^{\mathrm{m}}$ & $c_{\mathrm{L}}^{\mathrm{m}} c_{+1}^{\mathrm{m}}$ & $c_{\mathrm{L}}^{\mathrm{m}} c_{+2}^{\mathrm{m}}$ & $c_{-}^{\mathrm{m}}$ & $c_{\mathrm{L}}^{\mathrm{m}}$ & $c_{\mathrm{Y}}^{\mathrm{m}}$ \\
\hline-6 & -73.4 & $3.0 \times 10^{-10}$ & $3.1 \times 10^{-5}$ & $7.0 \times 10^{-5}$ & $7.0 \times 10^{-4}$ & $1.2 \times 10^{-8}$ & $2.3 \times 10^{-4}$ & $1.6 \times 10^{-3}$ \\
-5 & -66.6 & $1.8 \times 10^{-9}$ & $1.8 \times 10^{-5}$ & $3.9 \times 10^{-4}$ & $3.9 \times 10^{-4}$ & $1.5 \times 10^{-8}$ & $2.2 \times 10^{-4}$ & $1.6 \times 10^{-3}$ \\
-4 & -45.9 & $3.6 \times 10^{-9}$ & $3.6 \times 10^{-6}$ & $7.2 \times 10^{-4}$ & $7.2 \times 10^{-5}$ & $3.4 \times 10^{-8}$ & $2.0 \times 10^{-4}$ & $1.6 \times 10^{-3}$ \\
-3 & -17.6 & $4.0 \times 10^{-9}$ & $4.0 \times 10^{-7}$ & $7.9 \times 10^{-4}$ & $7.9 \times 10^{-6}$ & $1.0 \times 10^{-7}$ & $2.0 \times 10^{-4}$ & $1.6 \times 10^{-3}$ \\
-2 & +11.8 & $4.0 \times 10^{-9}$ & $4.0 \times 10^{-8}$ & $8.0 \times 10^{-4}$ & $8.0 \times 10^{-7}$ & $3.5 \times 10^{-7}$ & $2.0 \times 10^{-4}$ & $1.6 \times 10^{-3}$ \\
\hline
\end{tabular}

Fig. 4(d), parameters as 4(a) and $c_{+2}=1 \times 10^{-1} \mathrm{~mol} \mathrm{l}^{-1}, \beta_{1}=1 \times 10^{17} 1 \mathrm{~mol}^{-1}, \beta_{2}=1 \times 10^{13} \mathrm{l} \mathrm{mol}^{-1}$

\begin{tabular}{lllllllll}
\hline $\log c_{+1}$ & $E_{\mathrm{B} 2} / \mathrm{mV}$ & $c_{+1}^{\mathrm{m}}$ & $c_{+2}^{\mathrm{m}}$ & $c_{\mathrm{L}}^{\mathrm{m}} c_{+1}^{\mathrm{m}}$ & $c_{\mathrm{L}}^{\mathrm{m}} c_{+2}^{\mathrm{m}}$ & $c_{-}^{\mathrm{m}}$ & $c_{\mathrm{L}}^{\mathrm{m}}$ & $c_{\mathrm{Y}}^{\mathrm{m}}$ \\
\hline-6 & +157 & $5.0 \times 10^{-18}$ & $4.6 \times 10^{-13}$ & $7.7 \times 10^{-5}$ & $7.7 \times 10^{-4}$ & $9.0 \times 10^{-5}$ & $1.6 \times 10^{-4}$ & $1.6 \times 10^{-3}$ \\
-5 & +163 & $3.0 \times 10^{-17}$ & $3.0 \times 10^{-13}$ & $4.3 \times 10^{-4}$ & $4.3 \times 10^{-4}$ & $1.2 \times 10^{-4}$ & $1.4 \times 10^{-4}$ & $1.6 \times 10^{-3}$ \\
-4 & +179 & $8.8 \times 10^{-17}$ & $8.8 \times 10^{-14}$ & $8.2 \times 10^{-4}$ & $8.2 \times 10^{-5}$ & $2.1 \times 10^{-4}$ & $9.3 \times 10^{-5}$ & $1.6 \times 10^{-3}$ \\
-3 & +191 & $3.5 \times 10^{-16}$ & $3.5 \times 10^{-14}$ & $9.6 \times 10^{-4}$ & $9.6 \times 10^{-6}$ & $3.4 \times 10^{-4}$ & $2.8 \times 10^{-5}$ & $1.6 \times 10^{-3}$ \\
-2 & +192 & $3.1 \times 10^{-15}$ & $3.1 \times 10^{-14}$ & $1.0 \times 10^{-3}$ & $1.0 \times 10^{-6}$ & $3.9 \times 10^{-4}$ & $3.2 \times 10^{-6}$ & $1.6 \times 10^{-3}$ \\
\hline
\end{tabular}




\section{Appendix D}

The influence of association in the membrane phase on the potentiometric response of divalent cations. Starting parameters, $L_{\text {tot }}=1 \times 10^{-3} \mathrm{~mol} \mathrm{l}^{-1}, Y_{\text {tot }}=1.6$ $\times 10^{-3} \mathrm{~mol} \mathrm{l}^{-1}, k_{+1}=k_{+2}=k_{-}=1 \times 10^{-6}, c_{+1}(\mathrm{r})=$
$10^{-2} \mathrm{~mol} \mathrm{l}^{-1}, \quad \beta_{1}=1 \times 10^{17} \mathrm{~mol} \mathrm{l}^{11}, \beta_{2}=1 \times 10^{13}$ mol $1^{-1}, c_{+2}=10^{-1} \mathrm{~mol} \mathrm{l}^{-1}$. All values of $c$ are given in moles per litcr.

Fig. 5(a)

\begin{tabular}{lllllllll}
\hline $\log c_{+1}$ & $E_{\mathrm{B} 2} / \mathrm{mV}$ & $c_{+1}^{\mathrm{m}}$ & $c_{+2}$ & $c_{\mathrm{L}}^{\mathrm{m}} c_{+1}^{\mathrm{m}}$ & $c_{\mathrm{L}}^{\mathrm{m}} c_{+2}^{\mathrm{m}}$ & $c_{-}^{\mathrm{m}}$ & $c_{\mathrm{L}}^{\mathrm{m}}$ \\
\hline-6 & +157 & $5.0 \times 10^{-18}$ & $4.6 \times 10^{-13}$ & $7.7 \times 10^{-5}$ & $7.7 \times 10^{-4}$ & $9.0 \times 10^{-5}$ & $1.6 \times 10^{-4}$ & $1.6 \times 10^{-3}$ \\
-5 & +163 & $3.0 \times 10^{-17}$ & $3.0 \times 10^{-13}$ & $4.3 \times 10^{-4}$ & $4.3 \times 10^{-4}$ & $1.2 \times 10^{-4}$ & $1.4 \times 10^{-4}$ & $1.6 \times 10^{-3}$ \\
-4 & +179 & $8.8 \times 10^{-17}$ & $8.8 \times 10^{-14}$ & $8.2 \times 10^{-4}$ & $8.2 \times 10^{-5}$ & $2.1 \times 10^{-4}$ & $9.3 \times 10^{-5}$ & $1.6 \times 10^{-3}$ \\
-3 & +191 & $3.5 \times 10^{-16}$ & $3.5 \times 10^{-14}$ & $9.6 \times 10^{-4}$ & $9.6 \times 10^{-6}$ & $3.4 \times 10^{-4}$ & $2.8 \times 10^{5}$ & $1.6 \times 10^{-3}$ \\
-2 & +192 & $3.1 \times 10^{-15}$ & $3.1 \times 10^{-14}$ & $1.0 \times 10^{-3}$ & $1.0 \times 10^{-6}$ & $3.9 \times 10^{-4}$ & $3.2 \times 10^{-6}$ & $1.6 \times 10^{-3}$ \\
\hline
\end{tabular}

Fig. 5(b), parameters as 5(a) and $K_{-1}=K_{-2}=1 \times 10^{15} 1 \mathrm{~mol}^{-1}$

\begin{tabular}{|c|c|c|c|c|c|c|c|c|c|c|}
\hline $\log c_{+1}$ & $E_{\mathrm{B} 2} / \mathrm{mV}$ & $c_{+1}^{\mathrm{m}}$ & $c_{+2}^{\mathrm{m}}$ & $c_{\mathrm{L}}^{\mathrm{m}^{c^{m}}}$ & $c_{\mathrm{L}}^{\mathrm{m}} c_{+2}^{\mathrm{m}}$ & $c_{-}^{\mathbf{m}}$ & $c_{\mathrm{L}}^{\mathrm{m}}$ & $c_{\mathrm{Y}}^{\mathrm{m}}$ & $c_{\mathrm{M}}^{\mathbf{m}} c_{-1}^{\mathbf{m}}$ & $c_{\mathrm{M}}^{\mathrm{m}} c_{-2}^{\mathrm{m}}$ \\
\hline-6 & +227 & $2.1 \times 10^{-20}$ & $2.1 \times 10^{-15}$ & $2.1 \times 10^{-6}$ & $2.1 \times 10^{-5}$ & $1.4 \times 10^{-3}$ & $9.8 \times 10^{-4}$ & $1.6 \times 10^{-3}$ & $2.9 \times 10^{-8}$ & $2.9 \times 10^{-3}$ \\
\hline-5 & +227 & $2.1 \times 10^{-19}$ & $2.1 \times 10^{-15}$ & $2.0 \times 10^{-5}$ & $2.0 \times 10^{-5}$ & $10^{-3}$ & $10^{-4}$ & $10^{-3}$ & $2.9 \times 10^{-7}$ & $2.9 \times 10^{-3}$ \\
\hline-4 & +229 & $1.9 \times 10^{-18}$ & $1.9 \times 10^{-15}$ & $1.5 \times 10^{-4}$ & $1.5 \times 10^{-5}$ & $1.5 \times 10^{-3}$ & $8.3 \times 10^{-4}$ & $1.6 \times 10^{-3}$ & $2.7 \times 10^{-6}$ & $2.7 \times 10^{-3}$ \\
\hline-3 & +234 & $1.3 \times 10^{-17}$ & $1.3 \times 10^{-15}$ & $5.5 \times 10^{-4}$ & $5.5 \times 10^{-6}$ & $1.8 \times 10^{-3}$ & $4.4 \times 10^{-4}$ & $1.6 \times 10^{-3}$ & $2.3 \times 10^{-5}$ & $2.3 \times 10^{-3}$ \\
\hline-2 & +239 & $8.4 \times 10^{-17}$ & $8.4 \times 10^{-16}$ & $8.9 \times 10^{-4}$ & $8.9 \times 10^{-7}$ & $2.4 \times 10^{-3}$ & $1.1 \times 10^{-4}$ & $1.6 \times 10^{3}$ & $2.0 \times 10^{-4}$ & $2.0 \times 10^{-3}$ \\
\hline
\end{tabular}

Fig. 5(c), parameters as $5(\mathrm{a})$ and $K_{\mathrm{Y} 1}=K_{\mathrm{Y} 2}=1 \times 10^{15} 1 \mathrm{~mol}^{-1}$

\begin{tabular}{|c|c|c|c|c|c|c|c|c|c|c|}
\hline $\log c_{+1}$ & $E_{\mathrm{B} 2} / \mathrm{mV}$ & $c_{+1}^{\mathbf{m}}$ & $c_{+2}^{m}$ & $c_{\mathrm{L}}^{\mathbf{m}} c_{+1}^{\mathrm{m}}$ & $c_{\mathrm{L}}^{\mathrm{m}} c_{+2}^{\mathrm{m}}$ & $c_{-}^{\mathbf{m}}$ & $c_{\mathrm{L}}^{\mathrm{m}}$ & $c_{\mathrm{Y}}^{\mathrm{m}}$ & $c_{\mathrm{M}}^{\mathrm{m}} c_{\mathrm{Y} 1}^{\mathrm{m}}$ & $c_{\mathrm{M}}^{\mathrm{m}} c_{\mathrm{Y} 2}^{\mathrm{m}}$ \\
\hline-6 & +219 & $3.8 \times 10^{-20}$ & $3.8 \times 10^{-15}$ & $3.7 \times 10^{-6}$ & $3.7 \times 10^{-5}$ & $1.0 \times 10^{-3}$ & $9.6 \times 10^{-4}$ & $3.3 \times 10^{-4}$ & $1.3 \times 10^{-8}$ & $1.3 \times 10^{-3}$ \\
\hline-5 & +220 & $3.7 \times 10^{-19}$ & $3.7 \times 10^{-15}$ & $3.4 \times 10^{-5}$ & $3.4 \times 10^{-5}$ & $1.1 \times 10^{-3}$ & $9.3 \times 10^{-4}$ & $3.4 \times 10^{-4}$ & $1.3 \times 10^{-7}$ & $1.3 \times 10^{-3}$ \\
\hline-4 & +224 & $2.7 \times 10^{-18}$ & $2.7 \times 10^{-15}$ & $2.1 \times 10^{-4}$ & $2.1 \times 10^{-5}$ & $1.2 \times 10^{-3}$ & $7.7 \times 10^{-4}$ & $4.3 \times 10^{-4}$ & $1.2 \times 10^{-6}$ & $1.2 \times 10^{-3}$ \\
\hline-3 & +231 & $1.6 \times 10^{-17}$ & $1.6 \times 10^{-15}$ & $6.1 \times 10^{-4}$ & $6.1 \times 10^{-6}$ & $1.6 \times 10^{-3}$ & $3.8 \times 10^{-4}$ & $6.1 \times 10^{-4}$ & $9.8 \times 10^{-6}$ & $9.8 \times 10^{-4}$ \\
\hline-2 & +235 & $1.2 \times 10^{-16}$ & $1.2 \times 10^{-15}$ & $9.2 \times 10^{-4}$ & $9.2 \times 10^{-7}$ & $2.0 \times 10^{-3}$ & $7.9 \times 10^{-5}$ & $7.0 \times 10^{-4}$ & $8.2 \times 10^{-5}$ & $8.2 \times 10^{-4}$ \\
\hline
\end{tabular}

Fig. 5(d), parameters as 5(a) and $K_{\mathrm{Yz} 1}=K_{\mathrm{Yz}_{2}}=1 \times 10^{17} \mathrm{l}^{2} \mathrm{~mol}^{-2}$

\begin{tabular}{lllllllllll}
\hline $\log c_{+1}$ & $E_{\mathrm{B} 2} / \mathrm{mV}$ & $c_{+1}^{\mathrm{m}}$ & $c_{+2}^{\mathrm{m}}$ & $c_{\mathrm{L}}^{\mathrm{m}} c_{+1}^{\mathrm{m}}$ & $c_{\mathrm{L}}^{\mathrm{m}} c_{+2}^{\mathrm{m}}$ & $c_{-}^{\mathrm{m}}$ & $c_{\mathrm{L}}^{\mathrm{m}}$ & $c_{\mathrm{Y}}^{\mathrm{m}}$ & $c_{\mathrm{M}}^{\mathrm{m}}\left(c_{\mathrm{Y}}^{\mathrm{m}}\right)_{\mathrm{z}}$ & $c_{\mathrm{M}}^{\mathrm{m}}\left(c_{\mathrm{Y}}^{\mathrm{m}}\right)_{\mathrm{z}}$ \\
& & & & & & & & & & 1 \\
\hline-6 & +188 & $4.5 \times 10^{19}$ & $4.5 \times 10^{-14}$ & $3.0 \times 10^{-5}$ & $3.0 \times 10^{-4}$ & $3.0 \times 10^{-4}$ & $6.7 \times 10^{-4}$ & $3.7 \times 10^{-4}$ & $6.2 \times 10^{-9}$ & $6.2 \times 10^{-4}$ \\
-5 & +192 & $3.2 \times 10^{-18}$ & $3.2 \times 10^{-14}$ & $2.0 \times 10^{-4}$ & $2.0 \times 10^{-4}$ & $3.5 \times 10^{-4}$ & $6.1 \times 10^{-4}$ & $4.3 \times 10^{-4}$ & $5.9 \times 10^{-8}$ & $5.9 \times 10^{-4}$ \\
-4 & +204 & $1.3 \times 10^{-17}$ & $1.3 \times 10^{-14}$ & $5.3 \times 10^{-4}$ & $5.3 \times 10^{-5}$ & $5.6 \times 10^{-4}$ & $4.1 \times 10^{-4}$ & $6.2 \times 10^{-4}$ & $4.9 \times 10^{-7}$ & $4.9 \times 10^{-4}$ \\
-3 & +215 & $5.5 \times 10^{-17}$ & $5.5 \times 10^{-15}$ & $8.4 \times 10^{-4}$ & $8.4 \times 10^{-6}$ & $8.6 \times 10^{-4}$ & $1.5 \times 10^{-4}$ & $8.3 \times 10^{-4}$ & $3.8 \times 10^{-6}$ & $3.8 \times 10^{-4}$ \\
-2 & +218 & $4.2 \times 10^{-16}$ & $4.2 \times 10^{-15}$ & $9.8 \times 10^{-4}$ & $9.8 \times 10^{-7}$ & $1.1 \times 10^{-3}$ & $2.3 \times 10^{-5}$ & $8.8 \times 10^{-4}$ & $3.3 \times 10^{-5}$ & $3.3 \times 10^{-4}$ \\
\hline
\end{tabular}

Fig. 5(e), parameters as $5(\mathrm{a})$ and $K_{\mathrm{Y}-1}=K_{\mathrm{Y}-2}=1 \times 10^{17} \mathrm{l}^{2} \mathrm{~mol}^{-2}$

\begin{tabular}{|c|c|c|c|c|c|c|c|c|c|c|}
\hline $\log c_{+1}$ & $E_{\mathrm{B} 2} / \mathrm{mV}$ & $c_{+1}^{m}$ & $c_{+2}^{\mathrm{m}}$ & $c_{\mathrm{L}}^{\mathrm{m}} c_{+1}^{\mathrm{m}}$ & $c_{\mathrm{L}}^{\mathrm{m}} c_{+2}^{\mathrm{m}}$ & $c_{-}^{\mathrm{m}}$ & $c_{\mathrm{L}}^{\mathrm{m}}$ & $c_{\mathrm{Y}}^{\mathrm{m}}$ & $c_{\mathbf{M}}^{\mathfrak{m}} c_{-}^{\mathbf{m}} c_{\mathbf{Y} 1}$ & $c_{\mathrm{M}}^{\mathrm{m}} c_{-}^{\mathrm{m}} c_{\mathrm{Y} 2}$ \\
\hline-6 & +182 & $6.7 \times 10^{-19}$ & $6.7 \times 10^{-14}$ & $3.9 \times 10^{-5}$ & $3.9 \times 10^{-4}$ & $2.4 \times 10^{-4}$ & $5.8 \times 10^{-4}$ & $6.1 \times 10^{-4}$ & $9.9 \times 10^{-9}$ & $9.9 \times 10^{-4}$ \\
\hline-5 & +187 & $4.7 \times 10^{-18}$ & $4.7 \times 10^{-14}$ & $2.4 \times 10^{-4}$ & $2.4 \times 10^{-4}$ & $2.9 \times 10^{-4}$ & $5.2 \times 10^{-4}$ & $6.8 \times 10^{-4}$ & $10^{-8}$ & $10^{-4}$ \\
\hline-4 & +199 & $1.8 \times 10^{-17}$ & $1.8 \times 10^{-14}$ & $6.1 \times 10^{-4}$ & $6.1 \times 10^{-5}$ & $4.7 \times 10^{-4}$ & $3.3 \times 10^{-4}$ & $8.6 \times 10^{-4}$ & $7.4 \times 10^{-7}$ & $7.4 \times 10^{-4}$ \\
\hline-3 & +211 & $7.5 \times 10^{-17}$ & $7.5 \times 10^{-15}$ & $8.7 \times 10^{-4}$ & $8.7 \times 10^{-6}$ & $7.4 \times 10^{-4}$ & $1.2 \times 10^{-4}$ & $1.0 \times 10^{-3}$ & $5.7 \times 10^{-6}$ & $5.7 \times 10^{-4}$ \\
\hline-2 & +215 & $5.5 \times 10^{-16}$ & $5.5 \times 10^{-15}$ & $9.8 \times 10^{-4}$ & $9.8 \times 10^{-7}$ & $9.4 \times 10^{-4}$ & $1.8 \times 10^{-5}$ & $1.0 \times 10^{-3}$ & $5.3 \times 10^{-5}$ & $5.3 \times 10^{-4}$ \\
\hline
\end{tabular}




\section{Appendix E}

The influence of association in the membrane phase on the potentiometric response of divalent cations. Starting parameters, $L_{\text {tot }}=1 \times 10^{-3} \mathrm{~mol} \mathrm{l}^{-1}, Y_{\text {tot }}=1.6$ $\times 10^{-3} \mathrm{~mol} \mathrm{l}^{-1}, k_{+1}=k_{+2}=k_{-}=1 \times 10^{-6}, c_{+1}(\mathrm{r})=1$ $\times 10^{-2} \mathrm{~mol} \mathrm{l}^{-1}, \beta_{1}=1 \times 10^{17} \mathrm{~mol} \mathrm{l}^{-1}, \beta_{2}=1 \times 10^{13}$ mol 1-1, $c_{+2}=1 \times 10^{-1} \mathrm{~mol} \mathrm{l}^{-1}$. All values of $c$ are given in moles per liter.

Fig. 6(a)

\begin{tabular}{lllllllll}
\hline $\log c_{+1}$ & $E_{\mathrm{B} 2} / \mathrm{mV}$ & $c_{+1}^{\mathrm{m}}$ & $c_{+2}^{\mathrm{m}}$ & $c_{\mathrm{L}}^{\mathrm{m}} c_{+1}^{\mathrm{m}}$ & $c_{\mathrm{L}}^{\mathrm{m}} c_{+2}^{\mathrm{m}}$ & $c_{-}^{\mathrm{m}}$ & $c_{\mathrm{L}}^{\mathrm{m}}$ & $c_{\mathrm{Y}}^{\mathrm{m}}$ \\
\hline-6 & +157 & $5.0 \times 10^{-18}$ & $4.6 \times 10^{-13}$ & $7.7 \times 10^{-5}$ & $7.7 \times 10^{-4}$ & $9.0 \times 10^{-5}$ & $1.6 \times 10^{-4}$ & $1.6 \times 10^{-3}$ \\
-5 & +163 & $3.0 \times 10^{-17}$ & $3.0 \times 10^{-13}$ & $4.3 \times 10^{-4}$ & $4.3 \times 10^{-4}$ & $1.2 \times 10^{-4}$ & $1.4 \times 10^{-4}$ & $1.6 \times 10^{-3}$ \\
-4 & +179 & $8.8 \times 10^{-17}$ & $8.8 \times 10^{-14}$ & $8.2 \times 10^{-4}$ & $8.2 \times 10^{-5}$ & $2.1 \times 10^{-4}$ & $9.3 \times 10^{-5}$ & $1.6 \times 10^{-3}$ \\
-3 & +191 & $3.5 \times 10^{-16}$ & $3.5 \times 10^{-14}$ & $9.6 \times 10^{-4}$ & $9.6 \times 10^{-6}$ & $3.4 \times 10^{-4}$ & $2.8 \times 10^{-5}$ & $1.6 \times 10^{-3}$ \\
-2 & +192 & $3.1 \times 10^{-15}$ & $3.1 \times 10^{-14}$ & $1.0 \times 10^{-3}$ & $1.0 \times 10^{-6}$ & $3.9 \times 10^{-4}$ & $3.2 \times 10^{-6}$ & $1.6 \times 10^{-3}$ \\
\hline
\end{tabular}

Fig. $6(\mathrm{~b})$, parameters as $6(\mathrm{a})$ and $K_{\mathrm{LY} 1}=K_{\mathrm{LY} 2}=1 \times 10^{17} \mathrm{l}^{2} \mathrm{~mol}^{-2}$

\begin{tabular}{|c|c|c|c|c|c|c|c|c|c|c|}
\hline $\log c_{+1}$ & $E_{\mathrm{B} 2} / \mathrm{mV}$ & $c_{+1}^{\mathbf{m}}$ & $c_{+2}^{m}$ & $c_{\mathbf{L}}^{\mathbf{m}} c_{+1}^{\mathrm{m}}$ & $c_{\mathrm{L}}^{\mathrm{m}} c_{+2}^{\mathrm{m}}$ & $c_{-}^{\mathrm{m}}$ & $c_{\mathrm{L}}^{\mathrm{m}}$ & $c_{\mathrm{Y}}^{\mathrm{m}}$ & $c_{\mathrm{M}}^{\mathrm{m}} c_{\mathrm{L}}^{\mathbf{m}} c_{\mathbf{Y}}^{\mathrm{m}}$ & $c_{\mathrm{M}}^{\mathrm{m}} c_{\mathrm{L}}^{\mathrm{m}} c_{\mathrm{Y} 2}^{\mathrm{m}}$ \\
\hline-6 & +178 & $9.9 \times 10^{-19}$ & $9.9 \times 10^{-14}$ & $9.8 \times 10^{-6}$ & $9.8 \times 10^{-5}$ & $2.0 \times 10^{-4}$ & $9.9 \times 10^{-5}$ & $8.1 \times 10^{-4}$ & $7.9 \times 10^{-9}$ & $7.9 \times 10^{-4}$ \\
\hline-5 & +179 & $9.0 \times 10^{-18}$ & $9.0 \times 10^{-14}$ & $8.5 \times 10^{-5}$ & $8.5 \times 10^{-5}$ & $2.1 \times 10^{-4}$ & $9.5 \times 10^{-5}$ & $8.7 \times 10^{-4}$ & $7.4 \times 10^{-8}$ & $7.4 \times 10^{-4}$ \\
\hline-4 & +184 & $5.9 \times 10^{-17}$ & $5.9 \times 10^{-14}$ & $4.2 \times 10^{-4}$ & $4.2 \times 10^{-5}$ & $2.6 \times 10^{-4}$ & $7.0 \times 10^{-5}$ & $1.1 \times 10^{-3}$ & $4.7 \times 10^{-7}$ & $4.7 \times 10^{-4}$ \\
\hline-3 & +191 & $3.3 \times 10^{-16}$ & $3.3 \times 10^{-14}$ & $8.4 \times 10^{-4}$ & $8.4 \times 10^{-6}$ & $3.5 \times 10^{-4}$ & $2.5 \times 10^{-5}$ & $1.5 \times 10^{-3}$ & $1.2 \times 10^{-6}$ & $1.2 \times 10^{-4}$ \\
\hline-2 & +192 & $3.1 \times 10^{-15}$ & $3.1 \times 10^{-14}$ & $9.8 \times 10^{-4}$ & $9.8 \times 10^{-7}$ & $3.9 \times 10^{-4}$ & $3.1 \times 10^{-6}$ & $1.6 \times 10^{-3}$ & $1.6 \times 10^{-6}$ & $1.6 \times 10^{-5}$ \\
\hline
\end{tabular}

Fig. $6(\mathrm{c})$, parameters as $6(\mathrm{a})$ and $K_{\mathrm{L}-\mathrm{z} 1}=K_{\mathrm{L}-\mathrm{z} 2}=1 \times 10^{21} \mathrm{l}^{3} \mathrm{~mol}^{-3}$

\begin{tabular}{|c|c|c|c|c|c|c|c|c|c|c|}
\hline $\log c_{+1}$ & $E_{\mathrm{B} 2} / \mathrm{mV}$ & $c_{+1}^{\mathfrak{m}}$ & $c_{+2}^{\mathrm{m}}$ & $c_{\mathrm{L}}^{\mathrm{m}} c_{+1}^{\mathrm{m}}$ & $c_{\mathrm{L}}^{\mathrm{m}} c_{+2}^{\mathrm{m}}$ & $c_{-}^{\mathrm{m}}$ & $c_{\mathrm{L}}^{\mathrm{m}}$ & $c_{\mathrm{Y}}^{\mathrm{m}}$ & $c_{\mathrm{M}}^{\mathrm{m}} c_{\mathrm{L}}^{\mathrm{m}}\left(c_{-}^{\mathrm{m}}\right)_{z 1}$ & $c_{\mathrm{M}}^{\mathrm{m}} c_{\mathrm{L}}^{\mathrm{m}}\left(c_{-}^{\mathrm{m}}\right)_{\mathrm{z} 2}$ \\
\hline-6 & +138 & $2.1 \times 10^{-17}$ & $2.1 \times 10^{-12}$ & $7.5 \times 10^{-5}$ & $7.5 \times 10^{-4}$ & $4.4 \times 10^{-5}$ & $3.6 \times 10^{-5}$ & $1.6 \times 10^{-3}$ & $1.4 \times 10^{-9}$ & $1.4 \times 10^{-4}$ \\
\hline-5 & +145 & $1.2 \times 10^{-16}$ & $1.2 \times 10^{-12}$ & $4.1 \times 10^{-4}$ & $4.1 \times 10^{-4}$ & $5.8 \times 10^{-5}$ & $3.4 \times 10^{-5}$ & $1.6 \times 10^{-3}$ & $1.4 \times 10^{-8}$ & $10^{-4}$ \\
\hline-4 & +164 & $2.8 \times 10^{-16}$ & $2.8 \times 10^{-13}$ & $7.8 \times 10^{-4}$ & $7.8 \times 10^{-5}$ & $1.2 \times 10^{-4}$ & $2.8 \times 10^{-5}$ & $10^{-3}$ & $1.1 \times 10^{-7}$ & $10^{-4}$ \\
\hline-3 & +183 & $6.4 \times 10^{-16}$ & $6.4 \times 10^{-14}$ & $9.2 \times 10^{-4}$ & $9.2 \times 10^{-6}$ & $2.5 \times 10^{-4}$ & $1.4 \times 10^{-5}$ & $1.6 \times 10^{-3}$ & $5.9 \times 10^{-7}$ & $5.9 \times 10^{-5}$ \\
\hline-2 & +190 & $3.6 \times 10^{-15}$ & $3.6 \times 10^{-14}$ & $9.8 \times 10^{-4}$ & $9.8 \times 10^{-7}$ & $3.7 \times 10^{-4}$ & $2.7 \times 10^{-6}$ & $1.6 \times 10^{-3}$ & $1.3 \times 10^{-6}$ & $1.3 \times 10^{-5}$ \\
\hline
\end{tabular}

Fig. 6(d), parameters as 6(a) and $K_{\mathrm{LYz1}}=K_{\mathrm{LYz2}}=1 \times 10^{18} \mathrm{l}^{3} \mathrm{~mol}^{-3}$

\begin{tabular}{|c|c|c|c|c|c|c|c|c|c|c|}
\hline $\log c_{+1}$ & $E_{\mathrm{B} 2} / \mathrm{mV}$ & $c_{+1}^{\mathrm{m}}$ & $c_{+2}^{\mathrm{m}}$ & $c_{\mathrm{L}}^{\mathrm{m}} c_{+1}^{\mathrm{m}}$ & $c_{\mathrm{L}}^{\mathrm{m}} c_{+2}^{\mathrm{m}}$ & $c_{-}^{\mathrm{m}}$ & $c_{\mathrm{L}}^{\mathrm{m}}$ & $c_{\mathrm{Y}}^{\mathrm{m}}$ & $c_{\mathrm{M}}^{\mathrm{m}} c_{\mathrm{L}}^{\mathrm{m}}\left(c_{\mathrm{Y}}^{\mathrm{m}}\right)_{\mathrm{z} 1}$ & $c_{\mathrm{M}}^{\mathrm{m}} c_{\mathrm{L}}^{\mathrm{m}}\left(c_{\mathrm{Y}}^{\mathrm{m}}\right)_{\mathrm{z} 2}$ \\
\hline-6 & +151 & $7.7 \times 10^{-18}$ & $7.7 \times 10^{-13}$ & $6.9 \times 10^{-5}$ & $6.9 \times 10^{-4}$ & $7.2 \times 10^{-5}$ & $9.1 \times 10^{-5}$ & $1.5 \times 10^{-3}$ & $1.5 \times 10^{-9}$ & $1.5 \times 10^{-4}$ \\
\hline-5 & +160 & $3.9 \times 10^{-17}$ & $3.9 \times 10^{-13}$ & $4.0 \times 10^{-4}$ & $4.0 \times 10^{-4}$ & $1.0 \times 10^{-4}$ & $1.0 \times 10^{-4}$ & $1.5 \times 10^{-3}$ & $9.2 \times 10^{-9}$ & $9.2 \times 10^{-5}$ \\
\hline-4 & +178 & $9.4 \times 10^{-17}$ & $9.4 \times 10^{-14}$ & $8.1 \times 10^{-4}$ & $8.1 \times 10^{-5}$ & $2.1 \times 10^{-4}$ & $8.6 \times 10^{-5}$ & $1.6 \times 10^{-3}$ & $2.0 \times 10^{-8}$ & $2.0 \times 10^{-5}$ \\
\hline-3 & +191 & $3.5 \times 10^{-16}$ & $3.5 \times 10^{-14}$ & $9.6 \times 10^{-4}$ & $9.6 \times 10^{-6}$ & $3.4 \times 10^{-4}$ & $2.8 \times 10^{-5}$ & $1.6 \times 10^{-3}$ & $2.5 \times 10^{-8}$ & $2.5 \times 10^{-6}$ \\
\hline-2 & +192 & $3.1 \times 10^{-15}$ & $3.1 \times 10^{-14}$ & $1.0 \times 10^{-3}$ & $1.0 \times 10^{-6}$ & $3.9 \times 10^{-4}$ & $3.2 \times 10^{-6}$ & $1.6 \times 10^{-3}$ & $2.6 \times 10^{-8}$ & $2.6 \times 10^{-7}$ \\
\hline
\end{tabular}

\section{Appendix F}

The influence of association in the membrane phase on the potentiometric response of divalent cations. Starting parameters, $L_{\text {tot }}=1 \times 10^{-3} \mathrm{~mol} \mathrm{1}^{-1}, Y_{\text {tot }}=1.6$ $\times 10^{-3} \mathrm{~mol} \mathrm{l}^{-1}, k_{+1}=k_{+2}=k_{-}=1 \times 10^{-6}, c_{+1}(\mathrm{r})=1$ $\times 10^{-2} \mathrm{~mol} \mathrm{l}^{-1}, \beta_{1}=1 \times 10^{17} \mathrm{~mol} \mathrm{l}^{-1}, \beta_{2}=1 \times 10^{13}$ mol $1^{-1}, c_{+2}=1 \times 10^{-1} \mathrm{~mol} \mathrm{l}^{-1}$. All values of $c$ are given in moles per liter.

Fig. 7(a)

\begin{tabular}{|c|c|c|c|c|c|c|c|c|}
\hline $\log c+1$ & $E_{\mathrm{B} 2} / \mathrm{mV}$ & $c_{+1}^{\mathrm{m}}$ & $c_{+2}^{\mathrm{m}}$ & $c_{\mathrm{L}}^{\mathrm{m}} c_{+1}^{\mathrm{m}}$ & $c_{\mathrm{L}}^{\mathrm{m}} c_{+2}^{\mathrm{m}}$ & $c^{\mathbf{m}}$ & $c_{\mathrm{L}}^{\mathrm{m}}$ & $c_{\mathbf{Y}}^{\mathrm{m}}$ \\
\hline-6 & +157 & $5.0 \times 10^{-18}$ & $4.6 \times 10^{-13}$ & $7.7 \times 10^{-5}$ & $7.7 \times 10^{-4}$ & $9.0 \times 10^{-5}$ & $1.6 \times 10^{-4}$ & $1.6 \times 10^{-3}$ \\
\hline-5 & +163 & $3.0 \times 10^{-17}$ & $3.0 \times 10^{-13}$ & $4.3 \times 10^{-4}$ & $4.3 \times 10^{-4}$ & $1.2 \times 10^{-4}$ & $1.4 \times 10^{-4}$ & $1.6 \times 10^{-3}$ \\
\hline-4 & +179 & $8.8 \times 10^{-17}$ & $8.8 \times 10^{-14}$ & $8.2 \times 10^{-4}$ & $8.2 \times 10^{-5}$ & $2.1 \times 10^{-4}$ & $9.3 \times 10^{-5}$ & $1.6 \times 10^{-3}$ \\
\hline-3 & +191 & $3.5 \times 10^{-16}$ & $3.5 \times 10^{-14}$ & $9.6 \times 10^{-4}$ & $9.6 \times 10^{-6}$ & $3.4 \times 10^{-4}$ & $2.8 \times 10^{-5}$ & $1.6 \times 10^{-3}$ \\
\hline-2 & +192 & $3.1 \times 10^{-15}$ & $3.1 \times 10^{-14}$ & $1.0 \times 10^{-3}$ & $1.0 \times 10^{-6}$ & $3.9 \times 10^{-4}$ & $3.2 \times 10^{-6}$ & $1.6 \times 10^{-3}$ \\
\hline
\end{tabular}


Fig. $7\left(\right.$ b), parameters as $7(\mathrm{a})$ and $K_{\mathrm{L}-1}=K_{\mathrm{L}-2}=1 \times 10^{19} 1^{2} \mathrm{~mol}^{-2}$.

\begin{tabular}{lllllllllll}
\hline $\log c_{+1}$ & $E_{\mathrm{B} 2} / \mathrm{mV}$ & $c_{+1}^{\mathrm{m}}$ & $c_{+2}^{\mathrm{m}}$ & $c_{\mathrm{L}}^{\mathrm{m}} c_{+1}^{\mathrm{m}}$ & $c_{\mathrm{L}}^{\mathrm{m}} c_{+2}^{\mathrm{m}}$ & $c_{-}^{\mathrm{m}}$ & $c_{\mathrm{L}}^{\mathrm{m}}$ & $c_{\mathrm{Y}}^{\mathrm{m}}$ & $c_{\mathrm{M}}^{\mathrm{m}} c_{\mathrm{L}}^{\mathrm{m}} c_{-1}^{\mathrm{m}}$ & $c_{\mathrm{M}}^{\mathrm{m}} c_{\mathrm{L}}^{\mathrm{m}} c_{-2}^{\mathrm{m}}$ \\
\hline-6 & +33.3 & $7.5 \times 10^{-14}$ & $7.5 \times 10^{-9}$ & $5.5 \times 10^{-5}$ & $5.5 \times 10^{-4}$ & $7.3 \times 10^{-7}$ & $7.3 \times 10^{-9}$ & $1.6 \times 10^{-3}$ & $4.0 \times 10^{-9}$ & $4.0 \times 10^{-4}$ \\
-5 & +48.6 & $2.3 \times 10^{-13}$ & $2.3 \times 10^{-9}$ & $3.0 \times 10^{-4}$ & $3.0 \times 10^{-4}$ & $1.3 \times 10^{-6}$ & $1.3 \times 10^{-8}$ & $1.6 \times 10^{-3}$ & $4.0 \times 10^{-8}$ & $4.0 \times 10^{-4}$ \\
-4 & +91.7 & $7.9 \times 10^{-14}$ & $7.9 \times 10^{-11}$ & $5.5 \times 10^{-4}$ & $5.5 \times 10^{-5}$ & $7.1 \times 10^{-6}$ & $7.0 \times 10^{-8}$ & $1.6 \times 10^{3}$ & $3.9 \times 10^{-7}$ & $3.9 \times 10^{-4}$ \\
-3 & +143 & $1.5 \times 10^{-14}$ & $1.5 \times 10^{-12}$ & $6.5 \times 10^{-4}$ & $6.5 \times 10^{-6}$ & $5.3 \times 10^{-5}$ & $4.5 \times 10^{-7}$ & $1.6 \times 10^{-3}$ & $3.4 \times 10^{-6}$ & $3.4 \times 10^{-4}$ \\
-2 & +176 & $1.1 \times 10^{-14}$ & $1.1 \times 10^{-13}$ & $8.1 \times 10^{-4}$ & $8.1 \times 10^{-7}$ & $2.1 \times 10^{-4}$ & $7.4 \times 10^{-7}$ & $1.6 \times 10^{-3}$ & $1.7 \times 10^{-5}$ & $1.7 \times 10^{-4}$ \\
\hline
\end{tabular}

Fig. $7(\mathrm{c})$, parameters as $7(\mathrm{a})$ and $K_{\mathrm{L}-\mathrm{Y} 1}=K_{\mathrm{L}-\mathrm{Y} 2}=1 \times 10^{21} \mathrm{l}^{3} \mathrm{~mol}^{-3}$

\begin{tabular}{|c|c|c|c|c|c|c|c|c|c|c|}
\hline $\log c_{+1}$ & $E_{\mathrm{B} 2} / \mathrm{mV}$ & $c_{+1}^{\mathrm{m}}$ & $c_{+2}^{\mathrm{m}}$ & $c_{\mathrm{L}}^{\mathrm{m}} c_{+\mathrm{I}}^{\mathrm{m}}$ & $c_{\mathrm{L}}^{\mathrm{m}} c_{+2}^{\mathrm{m}}$ & $c_{-}^{\mathrm{m}}$ & $c_{\mathrm{L}}^{\mathrm{m}}$ & $c_{\mathrm{Y}}^{\mathbf{m}}$ & $c_{\mathrm{M}}^{\mathrm{m}} c_{\mathrm{L}}^{\mathrm{m}} c_{\mathrm{Y}}^{\mathrm{m}} c_{-1}^{\mathrm{m}}$ & $c_{\mathrm{M}}^{\mathrm{m}} c_{\mathrm{L}}^{\mathrm{m}} c_{\mathrm{Y}}^{\mathrm{m}} c_{-2}^{\mathrm{m}}$ \\
\hline-6 & +86.9 & $1.2 \times 10^{-15}$ & $1.2 \times 10^{-10}$ & $5.5 \times 10^{-5}$ & $5.5 \times 10^{-4}$ & $5.9 \times 10^{-6}$ & $4.8 \times 10^{-7}$ & $1.2 \times 10^{-3}$ & $3.9 \times 10^{-9}$ & $3.9 \times 10^{-4}$ \\
\hline-5 & +102 & $3.7 \times 10^{-15}$ & $3.7 \times 10^{-11}$ & $3.1 \times 10^{-4}$ & $3.1 \times 10^{-4}$ & $1.0 \times 10^{-5}$ & $8.4 \times 10^{-7}$ & $1.2 \times 10^{-3}$ & $3.9 \times 10^{-8}$ & $3.9 \times 10^{-4}$ \\
\hline-4 & +140 & $1.8 \times 10^{-15}$ & $1.8 \times 10^{-12}$ & $5.9 \times 10^{-4}$ & $5.9 \times 10^{-5}$ & $4.7 \times 10^{-5}$ & $3.2 \times 10^{-6}$ & $1.3 \times 10^{-3}$ & $3.5 \times 10^{-7}$ & $3.5 \times 10^{-4}$ \\
\hline-3 & +175 & $1.2 \times 10^{-15}$ & $1.2 \times 10^{-13}$ & $7.8 \times 10^{-4}$ & $7.8 \times 10^{-6}$ & $1.8 \times 10^{-4}$ & $6.5 \times 10^{-6}$ & $1.4 \times 10^{3}$ & $2.0 \times 10^{-6}$ & $2.0 \times 10^{-4}$ \\
\hline-2 & +189 & $4.2 \times 10^{-15}$ & $4.2 \times 10^{-14}$ & $9.4 \times 10^{-4}$ & $9.4 \times 10^{-7}$ & $3.4 \times 10^{-4}$ & $2.3 \times 10^{-6}$ & $1.6 \times 10^{-3}$ & $5.0 \times 10^{-6}$ & $5.0 \times 10^{-5}$ \\
\hline
\end{tabular}

\section{Appendix G}

The influence of the partition coefficient on the potentiometric response of monovalent cations. Starting parameters, $L_{\text {tot }}=1 \times 10^{-3} \mathrm{~mol} \mathrm{l}^{-1}, Y_{\text {tot }}=6 \times$ $10^{-3} \mathrm{~mol} \mathrm{l}^{-1}, k_{+1}=k_{+2}=k_{-}=1 \times 10^{-6}, c_{+1}(\mathrm{r})=1 \times$
$10^{-3} \mathrm{~mol} \mathrm{l}^{-1}, \quad c_{+2}(\mathrm{~s})=0.1 \mathrm{~mol} \mathrm{l}^{-1}, \quad \beta_{1}=1 \times 10^{9}$ $1 \mathrm{~mol}^{-1}, \beta_{2}=1 \times 10^{5} 1 \mathrm{~mol}^{-1}, u=1, u_{-}=10^{2}$. All values of $c$ are given in moles per liter.

Fig. 8(a)

\begin{tabular}{llllllllll}
\hline $\log c_{+1}$ & $E_{\mathrm{B} 2} / \mathrm{mV}$ & $E_{\mathrm{D}} / \mathrm{mV}$ & $c_{+1}^{\mathrm{m}}$ & $c_{+2}^{\mathrm{m}}$ & $c_{\mathrm{L}}^{\mathrm{m}} c_{+1}^{\mathrm{m}}$ & $c_{\mathrm{L}}^{\mathrm{m}} c_{+2}^{\mathrm{m}}$ & $c_{-}^{\mathrm{m}}$ & $c_{\mathrm{L}}^{\mathrm{m}}$ & $c_{\mathrm{Y}}^{\mathrm{m}}$ \\
\hline-6 & -125 & 0 & $1.3 \times 10^{-10}$ & $1.1 \times 10^{-5}$ & $1.1 \times 10^{-4}$ & $4.7 \times 10^{-4}$ & $7.7 \times 10^{-10}$ & $4.1 \times 10^{-4}$ & $6.0 \times 10^{-4}$ \\
-5 & -110 & 0 & $7.3 \times 10^{-10}$ & $7.3 \times 10^{-6}$ & $3.0 \times 10^{-4}$ & $3.0 \times 10^{-4}$ & $1.4 \times 10^{-9}$ & $4.1 \times 10^{-4}$ & $6.0 \times 10^{-4}$ \\
-4 & -66.9 & +0.01 & $1.4 \times 10^{-9}$ & $1.4 \times 10^{-6}$ & $5.4 \times 10^{-4}$ & $5.4 \times 10^{-5}$ & $7.4 \times 10^{-9}$ & $4.0 \times 10^{-4}$ & $6.0 \times 10^{-4}$ \\
-3 & -10.1 & +0.14 & $1.5 \times 10^{-9}$ & $1.5 \times 10^{-7}$ & $5.9 \times 10^{-4}$ & $5.9 \times 10^{-6}$ & $6.8 \times 10^{-8}$ & $4.0 \times 10^{-4}$ & $6.0 \times 10^{-4}$ \\
-2 & +48.7 & +1.5 & $1.5 \times 10^{-9}$ & $1.5 \times 10^{-8}$ & $6.0 \times 10^{-4}$ & $6.0 \times 10^{-7}$ & $7.3 \times 10^{-7}$ & $4.0 \times 10^{-4}$ & $6.0 \times 10^{-4}$ \\
Reference solution $E_{\mathrm{B} 1}=-10.4$ & $1.5 \times 10^{-9}$ & - & $6.0 \times 10^{-4}$ & - & $6.7 \times 10^{-10}$ & $4.0 \times 10^{-4}$ & $6.0 \times 10^{-4}$ \\
\hline
\end{tabular}

Fig. 8(b), parameters as $8(\mathrm{a})$ and $k_{-}=10^{-5}$

\begin{tabular}{|c|c|c|c|c|c|c|c|c|c|}
\hline $\log c_{+1}$ & $E_{\mathrm{B} 2} / \mathrm{mV}$ & $E_{\mathrm{D}} / \mathrm{mV}$ & $c_{+1}^{m}$ & $c_{+2}^{\mathbf{m}}$ & $c_{\mathrm{L}}^{\mathrm{m}} c_{+1}^{\mathrm{m}}$ & $c_{\mathrm{L}}^{\mathrm{m}} c_{+2}^{\mathrm{m}}$ & $c_{-}^{\mathrm{m}}$ & $c_{\mathbf{L}}^{\mathbf{m}}$ & $c_{\mathrm{Y}}^{\mathrm{m}}$ \\
\hline-6 & -125 & 0 & $1.3 \times 10^{-10}$ & $1.1 \times 10^{-5}$ & $1.1 \times 10^{-4}$ & $4.7 \times 10^{-4}$ & $7.7 \times 10^{-9}$ & $4.1 \times 10^{-4}$ & $6.0 \times 10^{-4}$ \\
\hline-5 & -110 & +0.01 & $7.3 \times 10^{-10}$ & $7.3 \times 10^{-6}$ & $3.0 \times 10^{-4}$ & $3.0 \times 10^{-4}$ & $1.4 \times 10^{-8}$ & $4.1 \times 10^{-4}$ & $6.0 \times 10^{-4}$ \\
\hline-4 & -67 & +0.14 & $1.4 \times 10^{-9}$ & $1.4 \times 10^{-6}$ & $5.4 \times 10^{-4}$ & $5.4 \times 10^{-5}$ & $7.4 \times 10^{-8}$ & $4.0 \times 10^{-4}$ & $6.0 \times 10^{-4}$ \\
\hline-3 & -10.2 & +1.38 & $1.5 \times 10^{-9}$ & $1.5 \times 10^{-7}$ & $6.0 \times 10^{-4}$ & $6.0 \times 10^{-6}$ & $6.8 \times 10^{-7}$ & $4.0 \times 10^{-4}$ & $6.0 \times 10^{-4}$ \\
\hline-2 & +48.0 & +11.8 & $1.5 \times 10^{-9}$ & $1.5 \times 10^{-8}$ & $6.1 \times 10^{-4}$ & $6.1 \times 10^{-7}$ & $7.1 \times 10^{-6}$ & $3.9 \times 10^{-4}$ & $6.0 \times 10^{-4}$ \\
\hline \multicolumn{3}{|c|}{ Reference solution $E_{\mathrm{BI}}=-10.4$} & $1.5 \times 10^{-9}$ & - & $6.0 \times 10^{-4}$ & - & $6.7 \times 10^{-9}$ & $4.0 \times 10^{-4}$ & $6.0 \times 10^{-4}$ \\
\hline
\end{tabular}

Fig. $8(\mathrm{c})$, parameters as $8(\mathrm{a})$ and $k_{-}=10^{-4}$

\begin{tabular}{|c|c|c|c|c|c|c|c|c|c|}
\hline $\log c_{+1}$ & $E_{\mathrm{B} 2} / \mathrm{mV}$ & $E_{\mathrm{D}} / \mathrm{mV}$ & $c_{+1}^{\mathrm{m}}$ & $c_{+2}^{\mathbf{m}}$ & $c_{\mathrm{L}}^{\mathrm{m}} c_{+1}^{\mathrm{m}}$ & $c_{\mathrm{L}}^{\mathrm{m}} c_{+2}^{\mathrm{m}}$ & $c_{-}^{\mathrm{m}}$ & $c_{\mathrm{L}}^{\mathrm{m}}$ & $c_{\mathbf{Y}}^{\mathbf{m}}$ \\
\hline-6 & -125 & +0.02 & $1.3 \times 10^{-10}$ & $1.1 \times 10^{-5}$ & $1.1 \times 10^{-4}$ & $4.7 \times 10^{-4}$ & $7.7 \times 10^{-8}$ & $4.1 \times 10^{-4}$ & $6.0 \times 10^{-4}$ \\
\hline-5 & -110 & +0.15 & $7.3 \times 10^{-10}$ & $7.3 \times 10^{6}$ & $3.0 \times 10^{-4}$ & $3.0 \times 10^{-4}$ & $1.4 \times 10^{-7}$ & $4.1 \times 10^{-4}$ & $6.0 \times 10^{-4}$ \\
\hline-4 & -67 & +1.4 & $1.4 \times 10^{-9}$ & $1.4 \times 10^{-6}$ & $5.5 \times 10^{-4}$ & $5.5 \times 10^{-5}$ & $7.4 \times 10^{-7}$ & $4.0 \times 10^{-4}$ & $6.0 \times 10^{-4}$ \\
\hline-3 & -10.9 & +11 & $1.5 \times 10^{-9}$ & $1.5 \times 10^{-7}$ & $6.0 \times 10^{-4}$ & $6.0 \times 10^{-6}$ & $6.6 \times 10^{-6}$ & $3.9 \times 10^{-4}$ & $6.0 \times 10^{-4}$ \\
\hline-2 & +42.4 & +44.2 & $1.9 \times 10^{-9}$ & $1.9 \times 10^{-8}$ & $6.6 \times 10^{-4}$ & $6.6 \times 10^{-7}$ & $5.7 \times 10^{-5}$ & $3.4 \times 10^{-4}$ & $6.0 \times 10^{-4}$ \\
\hline \multicolumn{3}{|c|}{ Reference solution $E_{\mathrm{B} 1}=-10.4$} & $1.5 \times 10^{-9}$ & - & $6.0 \times 10^{-4}$ & - & $6.7 \times 10^{-8}$ & $4.0 \times 10^{-4}$ & $6.0 \times 10^{-4}$ \\
\hline
\end{tabular}


Fig. $8(d)$, parameters as $8(a)$ and $k_{-}=10^{-3}$

\begin{tabular}{llclllllll}
\hline $\log c_{+1}$ & $E_{\mathrm{B} 2} / \mathrm{mV}$ & $E_{\mathrm{D}} / \mathrm{mV}$ & $c_{+1}^{\mathrm{m}}$ & $c_{+2}^{\mathrm{m}}$ & $c_{\mathrm{L}}^{\mathrm{m}} c_{+1}^{\mathrm{m}}$ & $c_{\mathrm{L}}^{\mathrm{m}} c_{+2}^{\mathrm{m}}$ & $c_{-}^{\mathrm{m}}$ & $c_{\mathrm{L}}^{\mathrm{m}}$ & $c_{\mathrm{Y}}^{\mathrm{m}}$ \\
\hline-6 & -125 & +0.21 & $1.3 \times 10^{-10}$ & $1.1 \times 10^{-5}$ & $1.1 \times 10^{-4}$ & $4.7 \times 10^{-4}$ & $7.7 \times 10^{-7}$ & $4.1 \times 10^{-4}$ & $6.0 \times 10^{-4}$ \\
-5 & -110 & +1.37 & $7.3 \times 10^{-10}$ & $7.3 \times 10^{-6}$ & $3.0 \times 10^{-4}$ & $3.0 \times 10^{-4}$ & $1.4 \times 10^{-6}$ & $4.1 \times 10^{-4}$ & $6.0 \times 10^{-4}$ \\
-4 & -67.7 & +10.5 & $1.4 \times 10^{-9}$ & $1.4 \times 10^{-6}$ & $5.5 \times 10^{-4}$ & $5.5 \times 10^{-5}$ & $7.2 \times 10^{-6}$ & $3.9 \times 10^{-4}$ & $6.0 \times 10^{-4}$ \\
-3 & -16.1 & +41.7 & $1.9 \times 10^{-9}$ & $1.9 \times 10^{-7}$ & $6.5 \times 10^{-4}$ & $6.5 \times 10^{-6}$ & $5.4 \times 10^{-5}$ & $3.5 \times 10^{-4}$ & $6.0 \times 10^{-4}$ \\
-2 & +18.8 & +74.3 & $4.8 \times 10^{-9}$ & $4.8 \times 10^{-8}$ & $8.3 \times 10^{-4}$ & $8.3 \times 10^{-7}$ & $2.3 \times 10^{-4}$ & $1.7 \times 10^{-4}$ & $6.0 \times 10^{-4}$ \\
Reference solution $E_{\mathrm{B} 1}=-10.4$ & $1.5 \times 10^{-9}$ & - & $6.0 \times 10^{-4}$ & - & $6.7 \times 10^{-7}$ & $4.0 \times 10^{-4}$ & $6.0 \times 10^{-4}$ \\
\hline
\end{tabular}

\section{Appendix H}

The influence of the association constant $\beta$ on the potentiometric response of monovalent cations. Starting parameters, $L_{\text {tot }}=1 \times 10^{-3} \mathrm{~mol} \mathrm{l}^{-1}, Y_{\text {tot }}=6 \times$ $10^{-4} \mathrm{~mol} \mathrm{1}{ }^{1}, k_{+1}=k_{+2}=k_{-}=1 \times 10^{-6}, c_{+1}(\mathrm{r})=1 \times$
$10^{-3} \mathrm{~mol} \mathrm{l}^{-1}, \quad c_{+2}(\mathrm{~s})=0.1 \mathrm{~mol} \mathrm{1^{-1 }}, \quad \beta_{1}=1 \times 10^{5}$ $1 \mathrm{~mol}^{-1}, \beta_{2}=1 \times 10^{1} 1 \mathrm{~mol}^{-1}, u=u_{-}=1$. All values of $c$ are given in moles per liter.

Fig. 10(a)

\begin{tabular}{|c|c|c|c|c|c|c|c|c|}
\hline $\log c_{+1}$ & $E_{\mathrm{B} 2} / \mathrm{mV}$ & $c_{+1}^{\mathbf{m}}$ & $c_{+2}^{\mathrm{m}}$ & $c_{\mathrm{L}}^{\mathrm{m}} c_{+1}^{\mathrm{m}}$ & $c_{\mathrm{L}}^{\mathrm{m}} c_{+2}^{\mathrm{m}}$ & $c_{-}^{\mathrm{m}}$ & $c_{\mathrm{L}}^{\mathrm{m}}$ & $c_{\mathbf{Y}}^{\mathbf{m}}$ \\
\hline-6 & -223 & $5.9 \times 10^{-9}$ & $5.9 \times 10^{-4}$ & $5.9 \times 10^{-7}$ & $5.9 \times 10^{-6}$ & $1.7 \times 10^{-11}$ & $9.9 \times 10^{-4}$ & $6.0 \times 10^{-4}$ \\
\hline-5 & -223 & $5.9 \times 10^{-8}$ & $5.9 \times 10^{-4}$ & $5.8 \times 10^{-6}$ & $5.8 \times 10^{-6}$ & $1.7 \times 10^{-11}$ & $9.9 \times 10^{-4}$ & $6.0 \times 10^{-4}$ \\
\hline-4 & -221 & $5.4 \times 10^{-7}$ & $5.4 \times 10^{-4}$ & $5.1 \times 10^{-5}$ & $5.1 \times 10^{-6}$ & $1.8 \times 10^{-11}$ & $9.4 \times 10^{-4}$ & $6.0 \times 10^{-4}$ \\
\hline-3 & -209 & $4.4 \times 10^{-6}$ & $3.4 \times 10^{-4}$ & $2.5 \times 10^{-4}$ & $2.5 \times 10^{-6}$ & $3.0 \times 10^{-11}$ & $7.4 \times 10^{-4}$ & $6.0 \times 10^{-4}$ \\
\hline-2 & -177 & $9.7 \times 10^{-6}$ & $9.7 \times 10^{-5}$ & $4.9 \times 10^{-4}$ & $4.9 \times 10^{-7}$ & $1.1 \times 10^{-10}$ & $5.1 \times 10^{-4}$ & $6.0 \times 10^{-4}$ \\
\hline
\end{tabular}

Fig. $10(\mathrm{~b})$, parameters as $10(\mathrm{a})$ and $u_{-}=10^{2}$

\begin{tabular}{llllllllll}
\hline $\log c_{+1}$ & $E_{\mathrm{B} 2} / \mathrm{mV}$ & $E_{\mathrm{D}} / \mathrm{mV}$ & $c_{+1}^{\mathrm{m}}$ & $c_{+2}^{\mathrm{m}}$ & $c_{\mathrm{L}}^{\mathrm{m}} c_{+1}^{\mathrm{m}}$ & $c_{\mathrm{L}}^{\mathrm{m}} c_{+2}^{\mathrm{m}}$ & $c_{-}^{\mathrm{m}}$ & $c_{\mathrm{L}}^{\mathrm{m}}$ \\
\hline-6 & -223 & 0 & $5.9 \times 10^{-9}$ & $5.9 \times 10^{-4}$ & $5.9 \times 10^{-7}$ & $5.9 \times 10^{-6}$ & $1.7 \times 10^{-11}$ & $9.9 \times 10^{-4}$ & $6.0 \times 10^{-4}$ \\
-5 & -223 & 0 & $5.9 \times 10^{-8}$ & $5.9 \times 10^{-4}$ & $5.8 \times 10^{-6}$ & $5.8 \times 10^{-6}$ & $1.7 \times 10^{-11}$ & $9.9 \times 10^{-4}$ & $6.0 \times 10^{-4}$ \\
-4 & -221 & 0 & $5.4 \times 10^{-7}$ & $5.4 \times 10^{-4}$ & $5.1 \times 10^{-5}$ & $5.1 \times 10^{-6}$ & $1.8 \times 10^{-11}$ & $9.4 \times 10^{-4}$ & $6.0 \times 10^{-4}$ \\
-3 & -209 & 0 & $4.4 \times 10^{-6}$ & $3.4 \times 10^{-4}$ & $2.5 \times 10^{-4}$ & $2.5 \times 10^{-6}$ & $3.0 \times 10^{-11}$ & $7.4 \times 10^{-4}$ & $6.0 \times 10^{-4}$ \\
-2 & -177 & 0 & $9.7 \times 10^{-6}$ & $9.7 \times 10^{-5}$ & $4.9 \times 10^{-4}$ & $4.9 \times 10^{-7}$ & $1.1 \times 10^{-10}$ & $5.1 \times 10^{-4}$ & $6.0 \times 10^{-4}$ \\
Reference solution $E_{\mathrm{B} 1}=-245$ & $1.4 \times 10^{-5}$ & - & $5.9 \times 10^{-4}$ & - & $7.1 \times 10^{-14}$ & $4.1 \times 10^{-4}$ & $6.0 \times 10^{-4}$ \\
\hline
\end{tabular}

Fig. 10(c), parameters as $10(\mathrm{a})$ and $\beta_{1}=10^{13} 1 \mathrm{~mol}^{-1}, \beta_{2}=10^{9} 1 \mathrm{~mol}^{-1}$

\begin{tabular}{lllllllll}
\hline $\log c_{+1}$ & $E_{\mathrm{B} 2} / \mathrm{mV}$ & $c_{+1}^{\mathrm{m}}$ & $c_{+2}^{\mathrm{m}}$ & $c_{\mathrm{L}}^{\mathrm{m}} c_{+1}^{\mathrm{m}}$ & $c_{\mathrm{L}}^{\mathrm{m}} c_{+2}^{\mathrm{m}}$ & $c_{-}^{\mathrm{m}}$ & $c_{\mathrm{L}}^{\mathrm{m}}$ & $c_{\mathrm{Y}}^{\mathrm{m}}$ \\
\hline-6 & +110 & $1.4 \times 10^{14}$ & $1.4 \times 10^{-9}$ & $5.5 \times 10^{-5}$ & $5.5 \times 10^{-4}$ & $7.1 \times 10^{-6}$ & $3.9 \times 10^{-4}$ & $6.0 \times 10^{-4}$ \\
-5 & +124 & $7.9 \times 10^{-14}$ & $7.9 \times 10^{-10}$ & $3.1 \times 10^{-4}$ & $3.1 \times 10^{-4}$ & $1.3 \times 10^{-5}$ & $3.9 \times 10^{-4}$ & $6.0 \times 10^{-4}$ \\
-4 & +163 & $1.7 \times 10^{-13}$ & $1.7 \times 10^{-10}$ & $6.0 \times 10^{-4}$ & $6.0 \times 10^{-5}$ & $5.7 \times 10^{-5}$ & $3.4 \times 10^{-4}$ & $6.0 \times 10^{-4}$ \\
-3 & +198 & $4.6 \times 10^{-13}$ & $4.6 \times 10^{-11}$ & $8.1 \times 10^{-4}$ & $8.1 \times 10^{-6}$ & $2.2 \times 10^{-4}$ & $1.8 \times 10^{-4}$ & $6.0 \times 10^{-4}$ \\
-2 & +208 & $3.0 \times 10^{-12}$ & $3.0 \times 10^{-11}$ & $9.7 \times 10^{-4}$ & $9.7 \times 10^{-7}$ & $3.7 \times 10^{-4}$ & $3.2 \times 10^{-5}$ & $6.0 \times 10^{-4}$ \\
\hline
\end{tabular}

Fig. $10(\mathrm{~d})$, parameters as $10(\mathrm{c})$ and $u_{-}=10^{2}$

\begin{tabular}{|c|c|c|c|c|c|c|c|c|c|}
\hline $\log c_{+1}$ & $E_{\mathrm{B} 2} / \mathrm{mV}$ & $E_{\mathrm{D}} / \mathrm{mV}$ & $c_{+1}^{\mathrm{m}}$ & $c_{+2}^{\mathrm{m}}$ & $c_{\mathrm{L}}^{\mathrm{m}} c_{+1}^{\mathrm{m}}$ & $c_{\mathrm{L}}^{\mathrm{m} / \mathrm{m}} c_{+2}^{\mathrm{m}}$ & $c_{-}^{\mathrm{m}}$ & $c_{\mathrm{L}}^{\mathrm{m}}$ & $c_{\mathrm{Y}}^{\mathrm{m}}$ \\
\hline-6 & +110 & +0.85 & $1.4 \times 10^{-14}$ & $1.4 \times 10^{-9}$ & $5.5 \times 10^{-5}$ & $5.5 \times 10^{-4}$ & $7.1 \times 10^{-6}$ & $3.9 \times 10^{-4}$ & $6.0 \times 10^{-4}$ \\
\hline-5 & +124 & +7.3 & $7.9 \times 10^{-14}$ & $7.9 \times 10^{-10}$ & $3.1 \times 10^{-4}$ & $3.1 \times 10^{-4}$ & $1.3 \times 10^{-5}$ & $3.9 \times 10^{-4}$ & $6.0 \times 10^{-4}$ \\
\hline-4 & +163 & +33.4 & $1.7 \times 10^{-13}$ & $1.7 \times 10^{-10}$ & $6.0 \times 10^{-4}$ & $6.0 \times 10^{-5}$ & $5.7 \times 10^{-5}$ & $3.4 \times 10^{-4}$ & $6.0 \times 10^{-4}$ \\
\hline-3 & +198 & +64 & $4.6 \times 10^{-13}$ & $4.6 \times 10^{-11}$ & $8.1 \times 10^{-4}$ & $8.1 \times 10^{-6}$ & $2.2 \times 10^{-4}$ & $1.8 \times 10^{-4}$ & $6.0 \times 10^{-4}$ \\
\hline-2 & +208 & +76.2 & $3.0 \times 10^{-12}$ & $3.0 \times 10^{-11}$ & $9.7 \times 10^{-4}$ & $9.7 \times 10^{-7}$ & $3.7 \times 10^{-4}$ & $3.2 \times 10^{-5}$ & $6.0 \times 10^{-4}$ \\
\hline \multicolumn{3}{|c|}{ Reference solution $E_{\mathrm{B} 1}=+225$} & $1.5 \times 10^{-13}$ & - & $6.1 \times 10^{-4}$ & - & $6.5 \times 10^{-6}$ & $3.9 \times 10^{-4}$ & $6.0 \times 10^{-4}$ \\
\hline
\end{tabular}

